University of Louisville ThinkIR: The University of Louisville's Institutional Repository

Electronic Theses and Dissertations

$8-2014$

\title{
Inducible tumor difference between rapid and slow rat Nat 2 congenic Fischer 344 rats administered methyl-nitrosourea.
}

Marcus W. Stepp

University of Louisville

Follow this and additional works at: https://ir.library.louisville.edu/etd

Part of the Pharmacy and Pharmaceutical Sciences Commons

\section{Recommended Citation}

Stepp, Marcus W., "Inducible tumor difference between rapid and slow rat Nat2 congenic Fischer 344 rats administered methylnitrosourea." (2014). Electronic Theses and Dissertations. Paper 1384.

https://doi.org/10.18297/etd/1384

This Master's Thesis is brought to you for free and open access by ThinkIR: The University of Louisville's Institutional Repository. It has been accepted for inclusion in Electronic Theses and Dissertations by an authorized administrator of ThinkIR: The University of Louisville's Institutional Repository. This title appears here courtesy of the author, who has retained all other copyrights. For more information, please contact thinkir@louisville.edu. 
INDUCIBLE TUMOR DIFFERENCE BETWEEN RAPID AND SLOW RAT NAT2 CONGENIC FISCHER 344 RATS ADMINISTERED METHYL-NITROSOUREA

By

Marcus W. Stepp

B.S., Rose Hulman Institute of Technology, 2010

\begin{abstract}
A Thesis
Submitted to the Faulty of the

School of Medicine of the University of Louisville

In Partial Fulfillment of the requirements

for the degree of

Master of Science

Department of Pharmacology and Toxicology

University of Louisville

Louisville, KY
\end{abstract}

August 2014 

INDUCIBLE TUMOR DIFFERENCE BETWEEN RAPID AND SLOW RAT NAT2 CONGENIC FISCHER 344 RATS ADMINISTERED METHYL-NITROSOUREA

$$
\text { By }
$$

Marcus W. Stepp

B.S., Rose Hulman Institute of Technology, 2010

A Thesis Approved on

August $1^{\text {st }} 2014$

By the following Thesis Committee

David W. Hein, PhD.

J. Christopher States, PhD.

David J. Samuelson, PhD.

Shirish S. Barve, PhD

Alfred B. Jenson, MD. 


\section{DEDICATION}

This thesis is dedicated to my caring parents

Mr. Kevin M. Stepp

And

Mrs. Wilma K. Stepp

for giving me so many opportunities in life and their continual support and encouragement. 


\section{ACKNOWLEDGEMENTS}

I would like to thank Dr. Hein, my mentor, for all of his support and guidance in the development of my thesis. Thank you to Mark Doll for all his dedicated help with several aspects of this thesis project. Additional thanks to my other committee members:

Dr. States, Dr. Samuelson, Dr. Barve, and Dr. Jenson

for their comments and suggestions. I would also like to acknowledge the help of Dr. Mary Ann Sanders, in teaching me pathology classifications and helping classify my pathology slides. 


\begin{abstract}
INDUCIBLE TUMOR DIFFERENCE BETWEEN RAPID AND SLOW RAT NAT2 CONGENIC FISCHER 344 RATS ADMINISTERED METHYL-NITROSOUREA

Marcus W. Stepp

August $1^{\text {st }} 2014$
\end{abstract}

Human arylamine $\mathrm{N}$-acetyltransferase 1 (NAT1) is a well-known phase II metabolic enzyme that has been associated with carcinogenesis. Its role in the biotransformation of aromatic and heterocyclic amine carcinogens has been investigated for many years, but more recent investigations focus on a possible endogenous role of human NAT1 in cancer initiation and progression. We conducted in vivo studies using homozygous Fischer 344 rats, congenic at the rat Nat2 locus for high (rapid) and low (slow) activity. Wistar Kyoto inbred rats were used to breed in the slow activity rat Nat2 locus into the Fischer 344 inbred rat, which contains the rapid activity rat Nat2 locus. The rat Nat2 gene is a functional ortholog for the human NAT1 because it has similar sequence and substrate specificity to human NAT1. Chemically induced breast tumors are produced in the rat following administration of methyl-nitrosourea (MNU). In this thesis, rapid and slow acetylator female congenic rats were administrated a single dose of $\mathrm{MNU}(50 \mathrm{mg} / \mathrm{kg})$ by intraperitoneal injection at three weeks of age. 
Weekly measurements of weights and palpable breast tumors were recorded. Palpable breast tumors showed a significantly shorter latency in rapid compared to slow acetylator congenic rats $(p=0.040)$. At 23 weeks post MNUadministration, rats were euthanized, and tumor and adjacent non-tumor tissue were collected. Tumors were found in $78 \%$ of the rapid acetylator congenic rats with an average \pm SEM of $1.78 \pm 0.7$ tumors per rat. In contrast, tumors were found in only $30 \%$ of slow acetylator congenic rats with an average of $0.5 \pm 0.3$ tumors per rat. Both tumor multiplicity and incidence approached significance ( $p=0.073$ and 0.069 , respectively) in this initial pilot experiment. Histopathology of the tumors classified the majority of the tumors as intraductal papillomas that were estrogen receptor positive by immunohistochemistry. The miRNA 574-3p was under expressed in intraductal papilloma breast tumors compared to normal tissues. These results suggest an important role for rat Nat2 in MNU-induced carcinogenesis and possibly carcinogenesis in general. Additional studies are proposed to confirm and understand the mechanism of rat Nat2's involvement in carcinogenesis. 


\section{TABLE OF CONTENTS}

\begin{tabular}{|c|c|}
\hline Acknowledgments.... & $\begin{array}{l}\text { Page } \\
\ldots \text { iv }\end{array}$ \\
\hline Abstract................. & $\ldots . . \mathrm{v}$ \\
\hline List of Figures.. & ......viii \\
\hline Introduction ............... & $\ldots . . .1$ \\
\hline Materials and Methods. & $\ldots . . .11$ \\
\hline
\end{tabular}

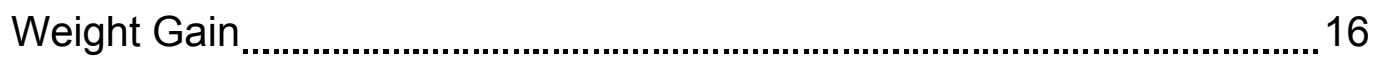

Palpable Breast Tumors ..................................................................................16

Tumor Multiplicity and Incidence ....................................................................

Whole Mount Mammary Gland ..................................................................... 17

Pathology of Breast Tumors ....................................................................2

miRNA Differences Between Tumor and Normal Tissue ...........................22

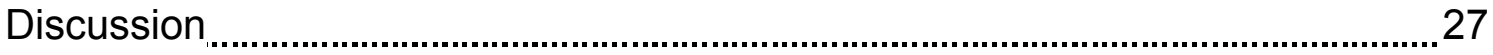

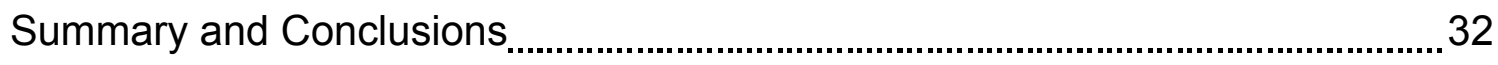

Future Directions

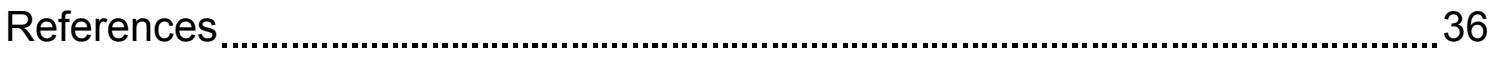

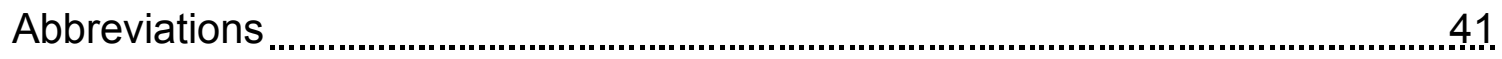

Curriculum Vitae 


\section{LIST OF FIGURES}

FIGURE

PAGE

1. Amino acid sequence comparison between Human NAT1 and Rat Nat2.......6

2. Mechanistic diagram for how MNU damages the genetic sequence ................

3. Average weights following MNU administration ..............................................18

4. Palpable breast tumors following administration of $\mathrm{MNU}$................................ 19

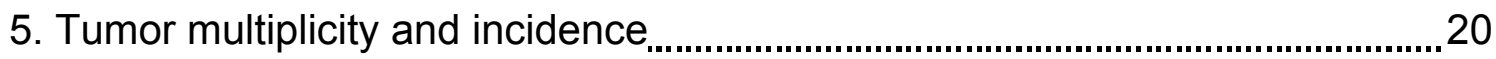

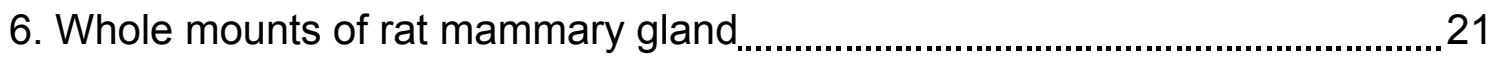

7. Photomicrographs of H\&E and immunohistochemistry slides ..........................24

8. Volcano plots of miRNA levels between different tissues...................................25

9. Scatter plots of validation qPCR results for selected miRNA 


\section{INTRODUCTION}

Human arylamine $\mathrm{N}$-acetyltransferase 1 (NAT1) is a phase II cytosolic isoenzyme responsible for the metabolism of arylamine xenobiotics, including such environmental and occupational carcinogens like 4-aminobiphenyl (ABP)[1]. NAT1 gene is located on the short arm of chromosome 8 (8p22), and is expressed in nearly all human tissues assayed $[2,3]$. NAT1 catalyzes both Nacetylation and $\mathrm{O}$-acetylation. The $\mathrm{N}$-acetylation of aromatic and heterocyclic amine xenobiotics results in the inactivation of compounds, and the inactivated compound is removed by urinary excretion. After N-hydroxylation of aromatic and heterocyclic amine xenobiotics by a cytochrome p450, O-acetylation catalyzed by NAT1 produces an unstable highly reactive nitrenium ion. This nitrenium ion is able to react with DNA and form DNA adducts, which if left unrepaired generate mutations that may result in cancer initiation. NAT1 is related to several cancer types by its ability to biotransform arylamine procarcinogens to active carcinogen forms. However recent findings suggest that human NAT1 activity is involved in cancer by an unknown mechanism independent of procarcinogen metabolism.

Research in cancer biology has provided insights into the connections of NAT1 and cancer cell proliferation and invasiveness. Overexpression of human NAT1 in the non-transformed breast epithelial cell line, HB4a, resulted in increased growth and survival. These modified cells also showed a resistance to etoposide treatment [4]. Calu3 cells, a colon carcinoma cell line, that are resistant 
to gemcitabine have higher expression of NAT1 [5]. In majority of human immortalized cells assayed there has been endogenous NAT1 expression/activity observed [6]. The use of a lentiviral shRNA expression system for human NAT1 knockdown in a human breast cancer cell line, MDA-MB-231, caused a decrease in cell proliferation and invasiveness [7]. Similarly, NAT1 knockdown in a human colon cancer cell line, HT-29 showed increased cell-cell contact inhibition [8]. Upregulation of E-cadherin was associated with knockdown of human NAT1, but there was no change in the transcription factors Snail, Twist, or Slug [8, 9]. The small molecule inhibitor, Rhod-o-hp, specific for human NAT1 showed that inhibition of NAT1 activity in MDA-MB-231 cells stops cell proliferation, inhibited anchorage-independent growth, and reduced the invasiveness of the cell [7]. All in vitro experiments indicate that human NAT1 plays some role in cancer cell proliferation and survival.

Microarray data on many different types of breast cancer showed NAT1 expression was clustered with estrogen receptor expression [10, 11]. This correlation between positive estrogen receptor (ER) status and human NAT1 was confirmed by additional microarray studies [12-15]. Immunohistochemistry showed higher human NAT1 levels in ER+ breast cancer samples when compared to ER- breast cancer [4]. Expression is also affected by the deletion of NAT1's chromosome region in some cancers. The deletion may explain why some cancer subtypes may have low expression of NAT1 [16]. Tumors, characterized based on which breast tissue the tumor arose from, showed luminal breast cancers with higher NAT1 expression than basal breast cancer 
$[11,17,18]$. A significant correlation has been observed between breast carcinomas expressing the highest levels of NAT1 and those that metastasized to the bone [19]. Also, elevated human NAT1 mRNA level has been shown to be associated with more invasive breast cancers [20]. All this evidence for the relationship of NAT1 with some subtypes of breast cancer has led some to state a possible role of NAT1 in classifying cancer molecular subtypes.

Human populations exhibit different NAT1 variant haplotypes, with NAT1*10 the most common variant haplotype. NAT1* 10 is presently defined by two SNPs 1088T>A (rs1057126) and 1095C >A (rs15561) in the 3' UTR (http://nat.mbg.duth.gr). NAT1*10 is associated with increased NAT1 activity in human bladder [21], colon [22], and liver [23]. NAT1*10 also is associated with higher cancer risk in some types of cancer. NAT1*10 has been associated with higher risk of developing cancer in the breast [24], colon/rectum [25, 26], lung [27], pancreas [28], and urinary bladder [29]. However, other studies have reported no association between $N A T 1^{*} 10$ and cancer risk [30, 31].

$N A T 1^{*} 14 B$ is the most common variant allele that is associated with a reduced acetylator activity. Allelic frequencies in American, German, French, and Canadian populations are less than 5\% [1]. However the allelic frequency of NAT1*14B in Lebanese population is about $24 \%$ [32]. NAT1*14B is defined presently by a SNP of nucleotide G560A (rs4986782), which is located in the open reading frame (ORF) (http://nat.mbg.duth.gr). G560A results in an amino acid substitution R187Q. The arginine for glutamine substitution is thought to destabilize the NAT1 structure. The use of homology modeling predicts that the 
substitution affects NAT1 binding of acetyl-coenzyme A, active site acetylation, catalytic activity, and substrate specificity [33]. NAT1*14B is associated with smoking induced cancer [34]. 4-aminobiphenyl (ABP) DNA adducts are elevated in cells that have been stably transfected with $N A T 1^{*} 14 B$ compared with cells transfected with $N A T 1^{*} 4$ (considered the reference haplotype) [35].

In summary human NAT1 is involved in cancer cell proliferation and survival. Human NAT1 has been found to correlate with aggressive forms of cancer and estrogen receptor positive breast cancer. Human NAT1 haplotypes that have the highest activity stand at a higher risk for certain types of cancer. This evidence shows that NAT1 has a role in cancer, but the exact mechanism of how it is involved is unknown.

Rat models share close similarity to humans with regard to $\mathrm{N}$ acetyltransferase gene and cancer. Rat models have been used previously for the study of arylamine $\mathrm{N}$-acetyltransferases [36-38]. Rat arylamine Nacetyltransferases are similar in sequence and function to human $\mathrm{N}$ acetyltransferases $[38,39]$. The residues 125,127 , and 129 are the amino acids in human NAT1 that determine substrate access to the active site, thus influencing substrate selectivity [40]. Rat Nat2 and human NAT1 are orthologs as shown by their amino acid sequences (Figure 1). Rat Nat2 and human NAT1 both contain Phe125, Arg127, Tyr129, which is predictive of their similar arylamine substrate selectivity. The C-terminal undecapeptide, which is involved in controlling acetyl-coenzyme A hydrolysis [41], is $100 \%$ identical when comparing rat Nat2 and human NAT1. Rat mammary cancer and human breast 
cancer are very similar, and the use of rat models is extremely valuable in the study of breast cancer [42]. Rat mammary glands are a source of hormone dependent neoplasms, which are similar to the most frequent human malignancy. Rats, like humans, have different haplotypes. Homozygous rapid (F344) and slow (WKY) acetylator inbred rats have been characterized as an animal model for investigations of the $\mathrm{N}$-acetylation polymorphism [37, 43]. Slow acetylator WKY inbred rats are homozygous for a rat Nat2 allele with four single nucleotide polymorphisms (SNPs): $\mathrm{G}^{361} \mathrm{~A} \quad\left(\mathrm{Val}^{121} \rightarrow \| \mathrm{ll}\right), \mathrm{G}^{399} \mathrm{~A}$ (synonymous), $\mathrm{G}^{522} \mathrm{~A}$ (synonymous), and $\mathrm{G}^{796} \mathrm{~A}\left(\mathrm{Val}^{266} \rightarrow \| l e\right)$, as compared to the Nat2 allele in the F344 rapid acetylator inbred rat [44] (Figure 1). These two inbred rat stains were used in the development of congenic rats that are utilized in this study. 


\section{FIGURE 1}

\begin{tabular}{|c|c|c|c|c|c|}
\hline \multirow[b]{2}{*}{ HUMAN NAT1-1 } & \multicolumn{2}{|l|}{ N-TERMINUS } & \multirow[b]{2}{*}{ LETLTDILQH } & \multirow[b]{2}{*}{ QIRAVPFENL } & \multirow[b]{2}{*}{ NIHCGDAMDL } \\
\hline & MDIEAYLERI & GYKKSRNKLD & & & \\
\hline RAT NAT2-1 & MDIEAYFERI & GYQSSRNKLD & LEELTEILQH & QIRAIPFENL & NIHCGESMEL \\
\hline HUMAN NAT1-51 & GLEAIFDQVV & RRNRGGWCLQ & VNHLLYWALT & TIGFETTMLG & GYVYSTPAKK \\
\hline RAT NAT2-51 & NLEVIFDQVV & RKKRGGWCLQ & VNHLLYWALT & KMGFEATMLG & GYVFNTPANK \\
\hline HUMAN NAT1-101 & YSTGMIHLLL & QVTIDGRNYI & VDAGFGRS $\mathbf{Y Q}$ & MWQPLELISG & KDQPQVPCVF \\
\hline RAT NAT2-101 & YSSGMIHLLV & QVTLSGKDYI & 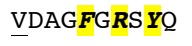 & MWEPLELTSG & KDQPQVPAIF \\
\hline HUMAN NAT1-151 & RLTEENGFWY & LDQIRREQYI & PNEEFLHSDL & LEDSKYRKIY & SFTLKPRTIE \\
\hline RAT NAT2-151 & RLTEENGTWY & LDQIRREQYV & PNQEFVNSDL & LEKNKYRKIY & SFTLEPRTIE \\
\hline HUMAN NAT1-201 & DFESMNTYLQ & TSPSSVFTSK & SFCSLQTPDG & VHCLVGFTLT & HRRFNYKDNT \\
\hline RAT NAT2-201 & DFESINTYLQ & TSPASLFTSK & SFCSLQTLEG & VHCLVGSTLT & YRRFSYKDNI \\
\hline HUMAN NAT1-251 & DLIEFKTLSE & EEIEKVLKNI & FNISLQRKLV & PKHGDRFFTI & $290 \mathrm{AA}$ \\
\hline RAT NAT2-251 & DLVEFKSLTE & EEIEDVLKTI & FGVSLERKLV & PKHGDRFFTI & $290 \mathrm{AA}$ \\
\hline & & & C-TERMINUS & & $\sim 83 \%$ \\
\hline
\end{tabular}

Figure 1. Amino acid sequence comparison between Human NAT1 and Rat Nat2. The gray highlighting indicates areas were the amino acids differ between the two enzymes. The two enzymes are $83 \%$ identical to each other. The yellow highlighted regions indicate the areas of importance to the enzymes, the cterminus tail and the three critical amino acids in the active site. The two enzymes share $100 \%$ similarity in the active site and c-terminus tail. In the rat sequence of amino acids there are two underlined amino acids, $\mathrm{Val}^{121}$ and $\mathrm{Val}^{266}$. Both valines are isoleucines in the slow phenotypic rats, where they are valines in rapid, wildtype, rats. 
The induction of breast tumors in rats provides useful observations, such as palpable tumors over the course of the experiment. Also, the use of a direct acting carcinogen will eliminate any differences caused by metabolism of a procarcinogen. The chemical chosen for this study is methyl-nitrosourea (MNU). Chemically induced breast tumors have been induced for several decades with the administration of MNU. MNU is a simple alkylating agent, which places a methyl group on oxygen and nitrogen of macromolecules, like DNA. It has been shown previously that sexually immature F344 rats (at 3 weeks of age) are more susceptible to mammary carcinogenic effects from MNU than mature rats (8 weeks of age) [45].

The mechanism for how MNU causes cancer is by DNA damage resulting from the alkylation of nitrogen and oxygen in DNA. $\mathrm{N}^{7}$-alkylguanine, $\mathrm{N}^{3}$ alkyladenine, and $\mathrm{O}^{6}$-alkylguanine account for $68 \%, 8 \%$, and $7.5 \%$ of total methylation after MNU treatment, respectively [46]. The $\mathrm{N}^{7}$ atom of guanine is the most vulnerable site for attack by alkylating agents; however $\mathrm{N}^{7}$-alkylguanine alone has no pronounced mutagenic and cytotoxic effect [47]. Alkylation of the $\mathrm{N}^{7}$ atom does cause chemical instability at the $\mathrm{N}$-glycosidic bond, causing spontaneous abasic/apurinic sites to form. Abasic sites also form in the repair of $\mathrm{N}^{7}$-alkylguanine by $\mathrm{N}$-alkylpurine DNA-glycosylases, enzymes in the BER pathway. The mutagenic and toxic effects of abasic sites have been well described previously [48]. $\mathrm{N}^{3}$-alkyladenine is not particularly mutagenic, but it is a cytotoxic DNA lesion because it is able to block replication and able to generate 
abasic sites [47]. $\mathrm{N}^{3}$-alkyladenine has been shown to cause sister chromatid exchange, chromosome gaps and breaks, $\mathrm{S}$ phase arrest, accumulation of p53, and apoptosis in mammalian cells [49]. $0^{6}$-alkylguanine is the primary mutagenic lesion under most conditions of alkylation damage to the genome causing $\mathrm{G} \rightarrow \mathrm{A}$ transitions after two replications $[47,50]$ (Figure 2). In addition to the point mutations following DNA replication, $\mathrm{O}^{6}$-alkylguanine can also result in mismatch repair-mediated DNA recombination and cell death [51]. Repair by mismatch repair system at $\mathrm{O}^{6}$-alkylG:T can form the "futile cycle". The "futile cycle" is where repair enzymes recognize mismatch of G:T and remove the newly incorporated thymine opposite of $\mathrm{O}^{6}$-alkylguanine. Then, the sequence is replicated again and the $\mathrm{O}^{6}$-alkylguanine preferentially pairs with thymine, once more, thus reinitiating the repair and replication cycle $[47,50,52,53]$. This persistent cycling of mismatch repair can generate a stabilized nick or gap in one strand of DNA, which may activate damage signaling pathways and DNA recombination [52]. Even with this futile cycling, it has been found that $\mathrm{O}^{6}$-alkylguanine lesions went from being $10 \%$ mutagenic in cells with repair capability to nearly $100 \%$ mutagenic in cells without DNA repair abilities [54]. When $0^{6}$-alkylguanine was examined with regards to epigenetics, $0^{6}$-alkylguanine was found to inhibit methylation of carbon-5 in cytosines by interfering with the binding of DNA methyltransferases. This interference eventually affected natural methylation causing the genome to become hypomethylated. Also, pairing of $\mathrm{O}^{6}$ alkylguanine:T can lead to DNA hypomethylation $[55,56]$. 
FIGURE 2

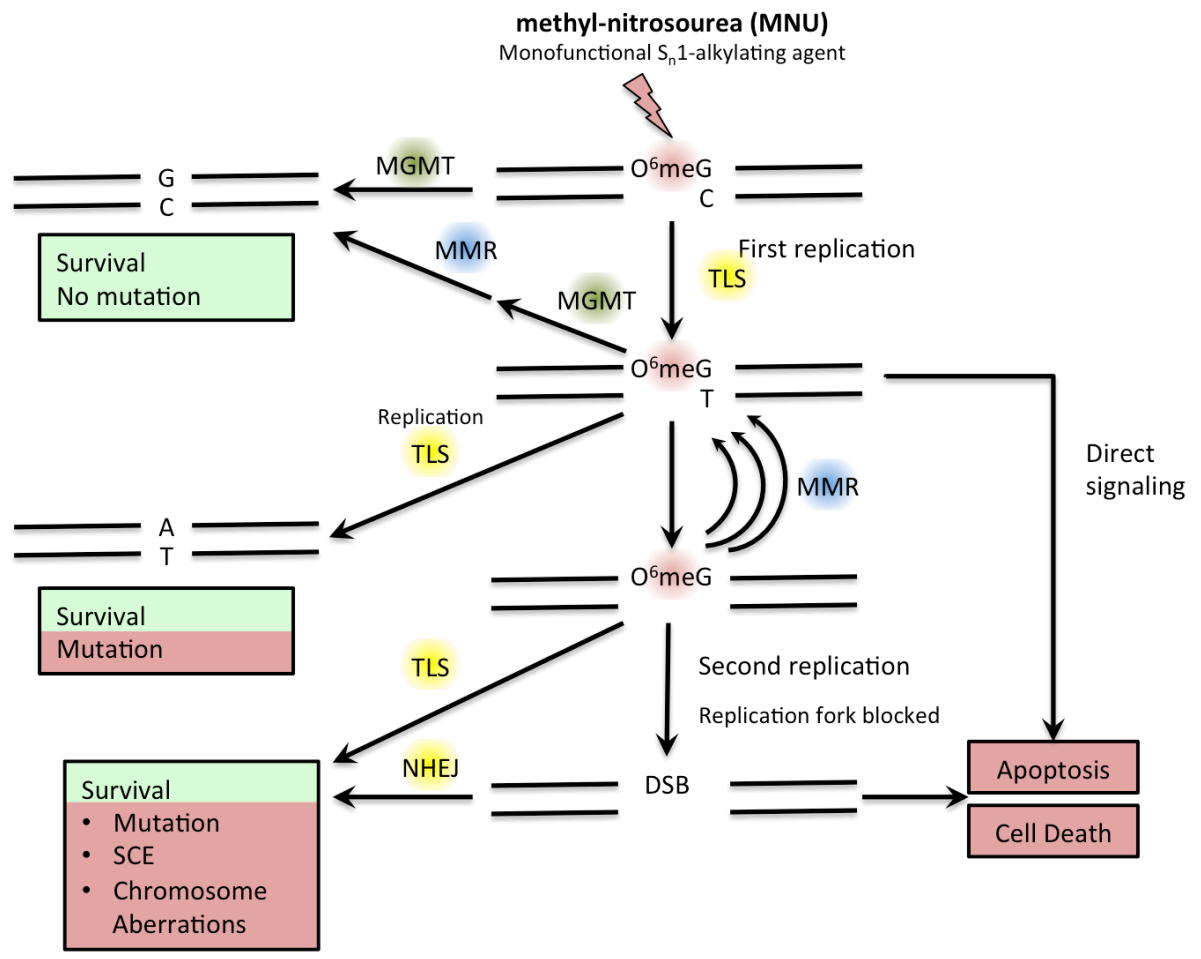

Figure 2. Mechanistic diagram for how MNU damages the genetic sequence. MNU alkylates guanine, which can be repaired immediately by $\mathrm{O}^{6}$ alkylguanine-DNA alkyltransferase (MGMT), also known as $0^{6}$-alkylguanine-DNA alkyltransferase (AGT). However if not repaired before replication, translesion DNA synthesis (TLS) will be done. TLS mismatches the nucleotide causing three possible pathways. The one on the left is that another TLS occurs resulting in a permanent mutation that can allow the cell to survive. The second possibility is on the right and is a direct signaling pathway that tells the cell to undergo apoptosis. The middle one is where the mismatch repair pathway tries to correct the mismatch of G:T and removes the newly incorporated thymine opposite of $\mathrm{O}^{6}$-alkylguanine. Then, the sequence is replicated again and the $\mathrm{O}^{6}$-alkylguanine preferentially pairs with thymine, once more, thus reinitiating the repair and replication cycle. This reoccurring cycling is termed the "futile cycle" Futile cycle can generate a stabilized nick or gap in one strand of DNA, which can cause replication fork collapse and a double strand DNA break (DSB). The DSB can be repaired by non-homologous end-joining (NHEJ) pathways, which can lead to cell survival but with mutations, sister chromatid exchange (SCE), or chromosomal aberrations. If the DSB is not repaired, cellular programing will be triggered to lead the cell into apoptosis. This figure has been modified from one previously published by Fu et al [57]. 
In the current study we investigated whether two different rat stains that are genetically identical except for the Nat2 gene differ in tumor formation after administration of the breast carcinogen MNU. Rat Nat2 is an ortholog of human NAT1. Based on the work done with human NAT1 in cell lines, microarray studies, and human populations, the hypothesis is that the rapid Nat2 rats (high activity) will develop more tumors than their slow Nat2 (low activity) peers. Also, rats with higher Nat2 activity should develop tumors sooner than rats with lower Nat2 activity. The study will use the chemical MNU, which causes direct DNA damage and is not a substrate for rat Nat2. Administration of MNU in three-weekold rats will induce tumors in a timely manner. 


\section{MATERIALS AND METHODS}

\section{Fischer 344 Congenic Nat2 Rats}

Congenic Fischer 344 rats were housed in University of Louisville Animal facility. The University of Louisville Institutional Animal Care and Use Committee approved the procedures used in this study. The construction of the rat Nat2 F344 congenic strain is described in a previous publication by the Hein lab [58]. Briefly, F344 (homozygous Nat2 rapid) males were mated to WKY (homozygous Nat2 slow) females to produce the obligate heterozygous F1 generation. F1 females were then backcrossed with F344 males. Heterozygous acetylator female progeny from each successive backcross were identified by rat Nat2 genotyping and mated with F344 rapid acetylator males. After ten generations of backcrossing, heterozygous acetylator brother/sister progeny were mated to produce the homozygous rapid and slow acetylator congenic rat Nat2 lines.

\section{Administration of methyl-nitrosourea}

Total of twenty female rats, ten rapid acetylator congenic rats and ten slow acetylator congenic rats, at three weeks of age were administered methylnitrosourea by a single intraperitoneal injection of $50 \mathrm{mg} / \mathrm{kg}(10 \mathrm{mg} / \mathrm{ml})$ solution dissolved in saline acidified with glacial acetic acid to $\mathrm{pH}$ 5.0. Three rapid and three slow acetylator control female animals were injected with vehicle.

\section{Weekly Observations}


Weekly measurement of individual rat weights was recorded and tracked post MNU administration. If a rat lost $10 \%$ of body weight and/or displayed bradykinesia/fatigue in moving, the rat was euthanized. Rats were palpated, and location and number of tumors recorded weekly.

\section{Tissue and Tumor Collection}

The duration of the experiment was 23 weeks. The rats were euthanized by $\mathrm{CO}_{2}$ asphyxiation followed by cervical dislocation. The rats were immediately dissected, and tumors with adjacent normal tissue were removed, with the tumors being divided in half. One half of the tumor with adjacent normal tissue attached was fixed in buffered formalin and used for histopathology. The second half had no adjacent tissue, and was flash frozen for later molecular analysis.

\section{Mammary Whole Mount}

The two caudal abdominal mammary glands, the fourth pair of mammary glands out of six pairs counting down from the pectoral area, of each rat were removed and whole mounted on glass slides for aluminum carmine staining. The slides were immersed in $70 \%$ ethanol for $1-2$ weeks to allow for fat to be removed from the gland. The slides were fixed with one part glacial acetic acid and three parts $100 \%$ ethanol for 60 minutes, washed in $70 \%$ ethanol for 15 minutes, $50 \%$ ethanol for 5 minutes, and rinsed in water for 5 minutes. The slides were left in aluminum carmine until stain had penetrated the entire tissue. The slides were then washed with $70 \%, 95 \%$, and $100 \%$ ethanol for 30 minutes each. Slides were then placed in xylene overnight, followed by storage in mineral oil for long-term storage. A dissection microscope was used to analyze the slides. 


\section{Pathology}

Tumor and adjacent normal tissue was placed in 10\% neutral buffered formalin solution. Samples were then given to Special Procedure Laboratory at the University of Louisville for processing. The Special Procedure Laboratory followed standard histological procedure, which is detailed below. In brief, tissue was paraffin embedded and sections cut at $5 \mu \mathrm{m}$. Sections were either used for hematoxylin and eosin (H\&E) staining or immunochemistry (estrogen receptor, progesterone receptor, and p63).

The H\&E staining was done by standard histological procedure. First step was drying slides in $58{ }^{\circ} \mathrm{C}$ oven until paraffin wax is melted. Next was a dewaxing step comprised of three changes of xylene at 5 minutes each, following rehydration to distilled water through graded ethanol $(100 \%$ ethanol two times at 5 minutes each, $95 \%$ ethanol two times at 5 minutes each, $50 \%$ ethanol once at 5 minutes, distilled water for at least 3 minutes). Next, slides were stained with hematoxylin for about three minutes, and then rinsed with distilled water to remove excess stain. Slides were then dipped into Tacha's bluing solution for 1015 seconds, and rinsed in running distilled water for 3 minutes. The slides were counter stained with Eosin $Y$ solution for 30 to 45 seconds. Slides were rinsed in $95 \%$ ethanol with ten quick dips, followed by ten dips $100 \%$ ethanol two times. The dehydrated slides were then dipped in three changes of xylene for about 20 seconds each. Finally 2 to 3 drops of permount were applied to each slide and a coverslip was applied. 
Immunochemistry slides were prepared by an automated system. In brief the steps were deparaffinization, epitope retrieval, $\mathrm{H}_{2} \mathrm{O}_{2}$ block for endogenous peroxidase, primary antibody, polymer detection, DAB (3,3'-diaminobenzidine) (positive staining), and counter staining with hematoxylin.

\section{miRNA}

Total RNA from flash frozen breast tissue was isolated by mirVana (Ambion, Foster City, CA). The cDNA was made from total RNA using Megaplex ${ }^{\mathrm{TM}}$ RT Primers Rodent Pool A and MultiScribe ${ }^{\mathrm{TM}}$ Reverse Transcriptase (Applied Biosystem, Foster City, CA). Applied Biosystems ${ }^{\circledR}$ TaqMan ${ }^{\circledR}$ Rodent MicroRNA A Array v2.0 (Applied Biosystems, Foster City, CA), which contains 384 TaqMan® MicroRNA Assays was used to identify miRNAs of interest. The qPCR mix was comprised of supplied Megaplex ${ }^{\mathrm{TM}}$ PreAmp Primers Rodent Pool A and TaqMan® Gene Expression Master Mix (Applied Biosystems, Foster City, CA). Panel plates were run on a $7900 \mathrm{HT}$ Fast Real-Time PCR System (Applied Biosystems, Foster City, CA). Array data were analyzed with ExpressionSuite Software. The miRNAs found to be significantly different between normal and tumor tissue were validated independently by using commercially available reverse transcriptase primers and Taqman primers for mir574-3p (\#002349), miR-344 (\#001063), miR-543 (\#003276), and U6 snRNA (\#001973)(Applied Biosystems, Foster City, CA). The qPCR validation reactions were run on a Step One Plus Real-Time PCR System (Applied Biosystems, Foster City, CA) as directed by the manufacturer. 


\section{Statistics}

Statistical differences were determined using Prism Software by Graphpad (La Jolla, CA). Two-way analysis of variance was used to compare the curves of weight gain over time followed by Bonferroni post hoc test. Log-rank (MantelCox) test was used to compare the Kaplan-Meier graphs of palpable tumors. Whitney-Mann U-test was used to test for difference in the tumor multiplicity. Fisher's exact test was used to determine if tumor incidence was significantly different. A one-way analysis of variance was used to measure miRNA expression differences followed by Bonferroni post hoc test. 


\section{RESULTS}

\section{Weight gain}

Weekly weights demonstrated a continual weight gain in both rapid and slow untreated congenic rats. Rapid and slow treated congenic rats demonstrated initial decrease in weight gain after MNU administration, followed by normal weight gain after the second week. Treated congenic rats never reached the same weight as the untreated counterparts at any point during the

experiment, as shown by a two-way ANOVA $(p=0.001)$ (Figure 3$)$. Bonferroni post hoc test shows that rapid and slow controls were not significantly different $(p>0.05)$, and that $\mathrm{MNU}$-treated rapid and slow acetylator rat weights were significantly different from each other $(p<0.001)$ (Figure 3$)$.

\section{Palpable breast tumors}

Palpable tumors showed a significantly shorter latency in rapid compared to slow acetylator congenic rats. The earlier onset of tumors in rapid Nat2 rats is shown by a Kaplan-Meier analysis (Figure 4). Comparing the palpable tumor curves of rapid and slow Nat2 congenic rats with Log-rank (Mantel-Cox) Test shows a statistical difference between rapid and slow acetylator rats with a $p=0.040$. In comparing two groups on a Kaplan-Meier plot over time, a hazard ratio is a common statistical measurement. The higher the hazard ratio the more likely subjects of one group will display an affect compared to another group per unit of time. In this experiment, the hazard ratio is 4.58 comparing rapid congenic rats to 
slow congenic rats with a $95 \%$ confidence interval of 1.072 to 19.59 . This hazard ratio means that the rapid congenic rats will develop tumors 4.53 times more frequently per week than slow congenic rats. Since the confidence interval does not contain the value of one, the hazard ratio is significant $(p<0.05)$.

\section{Tumor multiplicity and incidence}

Tumors were found in over half $(78 \%)$ of the rapid acetylator congenic rats with an average of $1.78 \pm 0.7$ tumors per rat. In contrast, tumors were found in less than half $(30 \%)$ of slow acetylator congenic rats with an average of $0.5 \pm 0.3$ tumors per rat. Both tumor multiplicity and incidence differed between rapid and slow acetylator rats just missing significance $(p=0.073$ and 0.069 , respectively) in this experiment. Tumor multiplicity was statistically tested with a two-tailed Mann Whitney U-test (Figure 5, left). Tumor incidence was statistically analyzed with a $2 \times 2$ contingency table and performing a Fisher's exact test (Figure 5, right).

\section{Whole mount mammary glands}

Whole mounts of rat mammary $D$ glands, the fourth pair of mammary glands out of six pairs counted down from the pectoral area, were made for every rat. Of the thirty-eight slides for MNU-treated congenic rats examined (18 slides for rapid and 20 slides for slow Nat2 congenic rats) only one slide showed anything abnormal in ductal morphology when compared to control untreated rats. The one slide was from the left side of a rapid congenic rat (Figure 6). The abnormal growths in the mammary ducts were classified by H\&E as hyperplasia. 


\section{FIGURE 3}

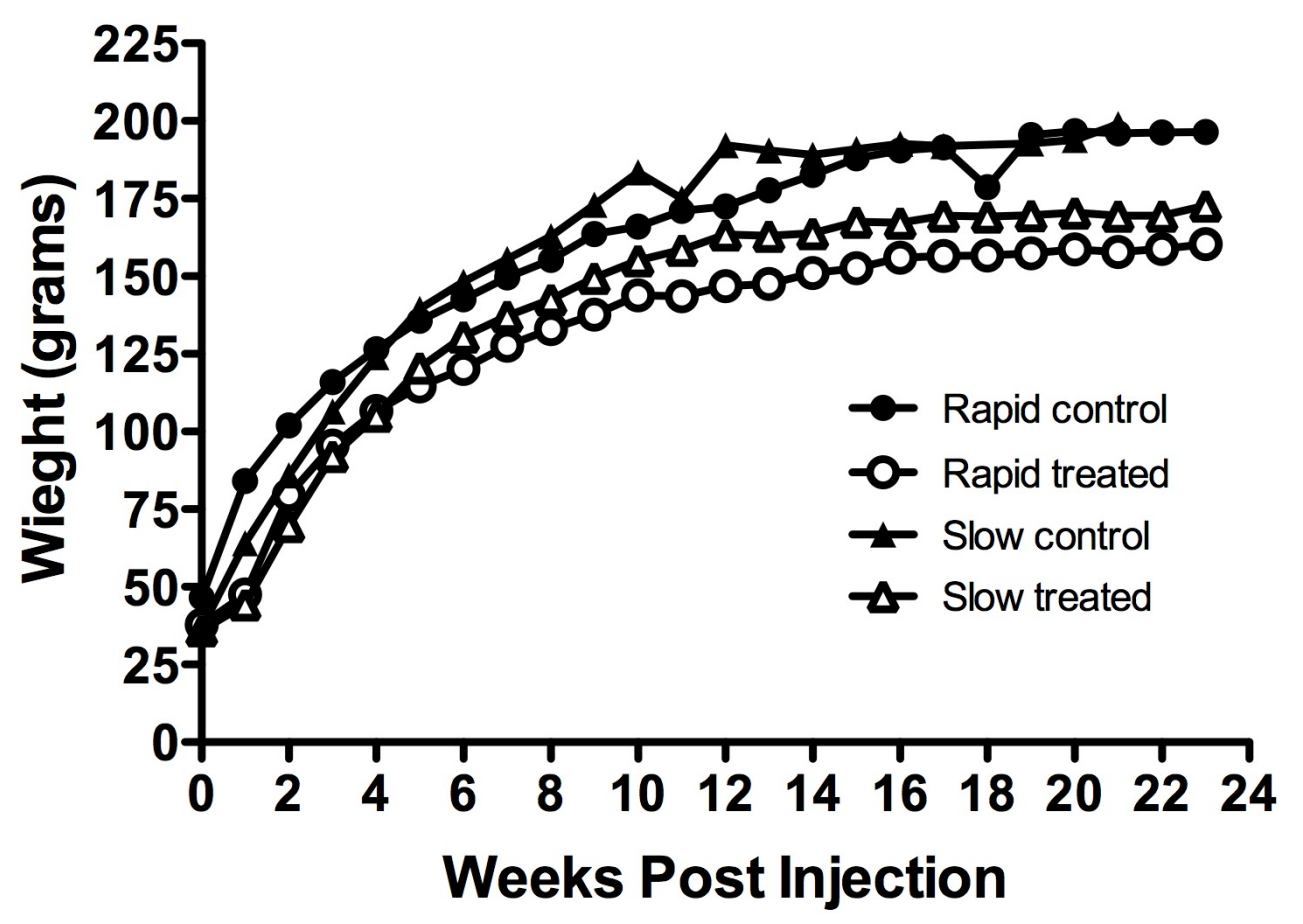

Figure 3. Average weights following MNU administration

Average weights of the congenic rats treated and untreated with MNU over the 23-week period following administration. Treated rapid acetylator rats are open circles, and untreated rapid acetylator rats are solid circles. The treated slow acetylator rats are open triangles, and the untreated slow acetylator rats are solid triangles. The individual points represent the average per group. Statistical significance was found with a 2-way ANOVA $(p<0.001)$. Bonferroni post-test shows that rapid and slow controls were not significantly different $(p>0.05)$, and that MNU-treated rapid and slow acetylator rat weights were significantly different from each other $(p<0.001)$. 


\section{FIGURE 4}

\section{Palpable Rat Breast Tumors}

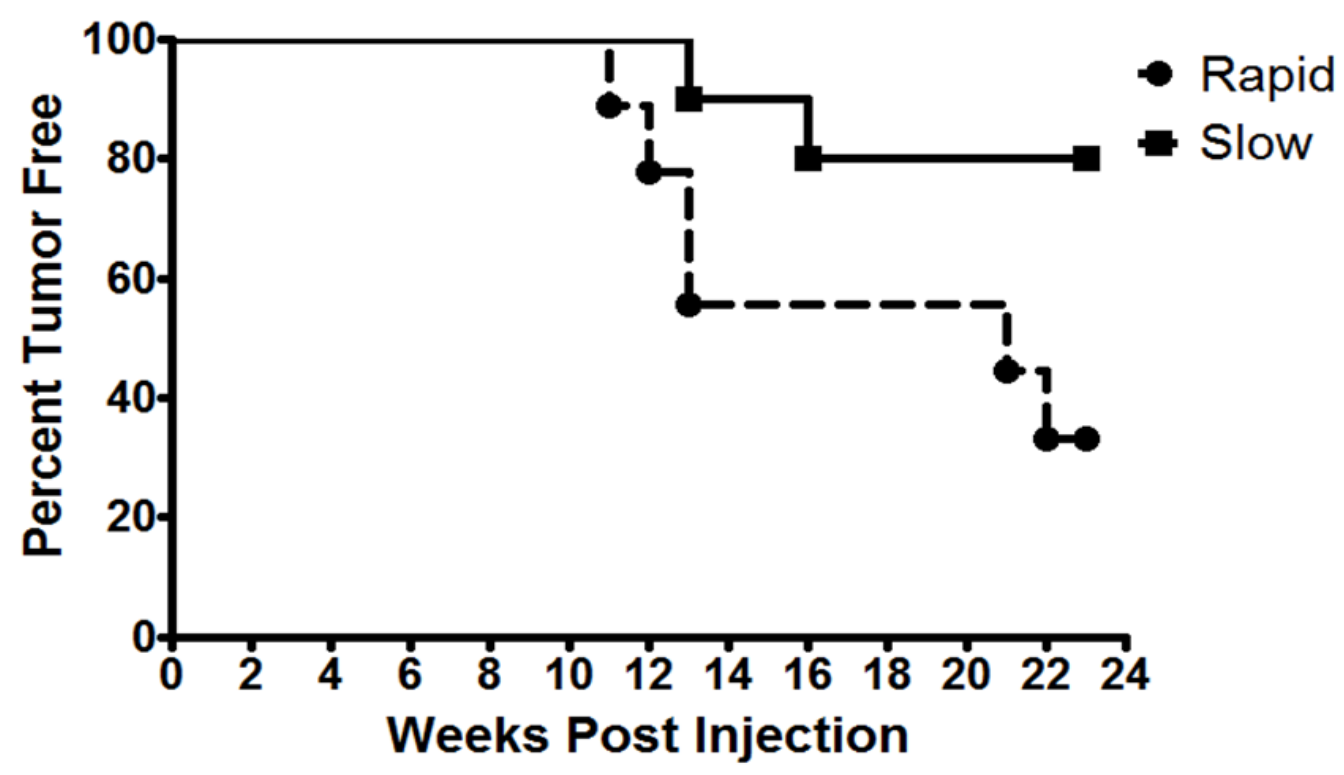

Figure 4. Palpable breast tumors following administration of MNU.

Kaplan-Meier plot illustrating the onset of tumors in the rapid and slow Nat2 congenic rats over 23 weeks post-administration of MNU. Rapid acetylator congenic rats (circle $\bullet$ and dash line) showed a significantly shorter latency compared to slow acetylator congenic rats (square $\mathbf{m}$ and solid line) when tested by a Log-Rank (Mantel-Cox) test $(p=0.040)$. The first tumor was palpable at 11 weeks post-injection in rapid acetylator congenic rats and at 13 weeks in slow acetylator congenic rats. 


\section{FIGURE 5}

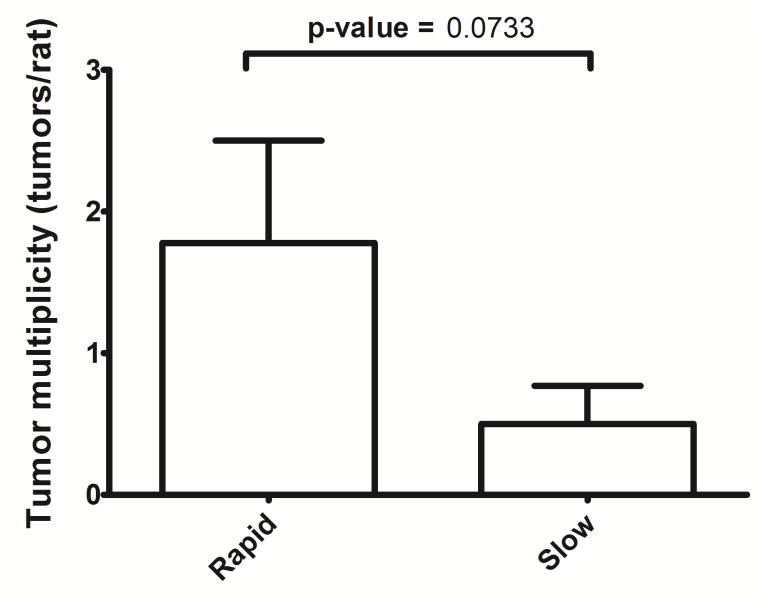

Congenic Rat Model (rat Nat2)

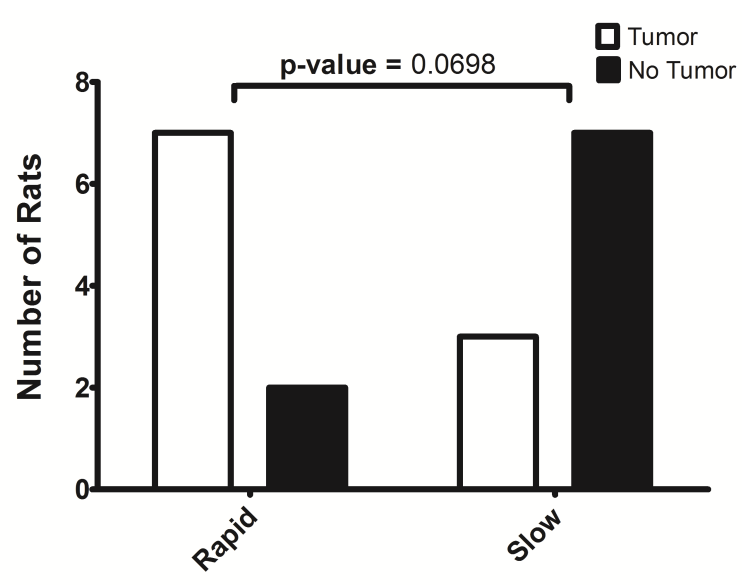

Congenic Rat Model (rat Nat2)

Figure 5. Tumor multiplicity and incidence.

Tumor multiplicity and tumor incidence found per congenic rat strain. Left: Multiplicity of tumors in rapid versus slow Nat2 congenic rat model displayed as the average and SEM. Significance was tested using a Mann Whitney U-test $(p=$ 0.0733). Right: Incidence of tumors in rapid versus slow Nat2 congenic rat models graphically displayed in a $2 \times 2$ contingency table. Significance was tested using a Fisher's exact test $(p=0.0698)$. 


\section{FIGURE 6}
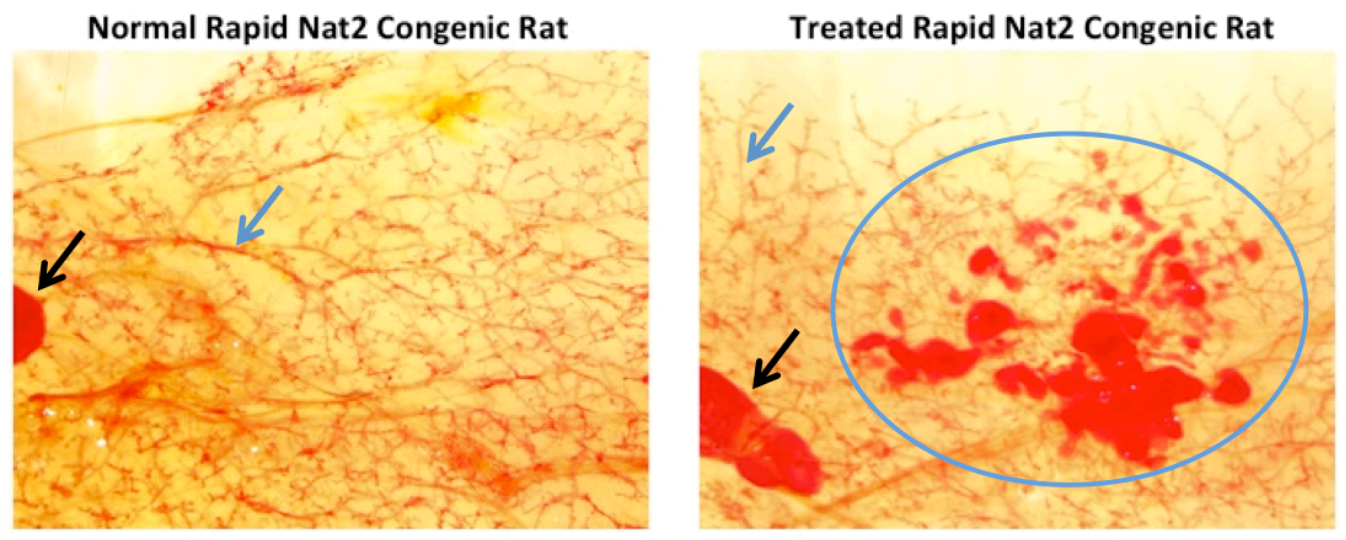

Figure 6. Whole mounts of rat mammary gland.

Left: A slide from a normal untreated rapid congenic rat. The red lines are mammary ducts (blue arrow). The large red mass on the far left is a lymph node (black arrow). Right: The only abnormal growth observed in over 38 slides of treated congenic rats. The slide is from a MNU-treated rapid Nat2 congenic rat. The red lines are normal mammary ducts (blue arrow) and the larger red mass on the left is a lymph node (black arrow). The cluster of smaller and larger red masses is the abnormal growth in the mammary duct (circled in blue). Upon H\&E classification, the mammary ducts were classified as hyperplasia. 


\section{Pathology of Breast Tumors}

Pathological evaluation of the tumors classified the majority of the tumors as intraductal papillomas, with the exception of one treated (rapid acetylator) rat classified as a highly invasive carcinoma. Normal rat mammary glands are composed of highly branched system of ducts and terminal secretory alveoli. The mammary ducts are surrounded by adipose tissue and contain two main cell types epithelial and myoepithelial. Intraductal papillomas are proliferation of epithelial papillary cells from the wall of a cyst into the lumen with overlaying fibrovascular core (Figure 7). Collagenous spherulosis, milky secretion, is a common occurrence in intraductal papillomas. We found that of the intraductal papillomas tested, all were estrogen receptor (ER) positive, benign tumors, determined by use of p63 antibodies for myoepithelial cells (Figure 7). ER expression is localized to the luminal lining cells, which indicates epithelial cells (cells known to line the cystic space) as ER positive (Figure 7). Myoepithelial cells express the p63 protein, which by immunohistochemistry are the cells stained brown (Figure 7). The p63 positive cells show normal cell compartmentalization order, which is indicative of a benign tumor.

\section{miRNA differences between tumor and normal tissue.}

TaqMan® Rodent MicroRNA A Array v2.0 analysis showed two miRNAs that differed significantly between rapid intraductal papilloma tumor tissue and rapid adjacent normal tissue; mmu-miR-574-3p (0.114- fold, $p=0.037)$ and $\mathrm{mmu}$ miR-344 (5.176- fold, $p=0.015)$ (Figure $8 \mathrm{~A})$. An additional miRNA of significance was found comparing rapid intraductal papilloma tumor tissue and rapid control 
normal tissue, mmu-miR-543-3p (48.2- fold, $p=0.007$ ) (Figure 8 B). Validation was conducted on all the above miRNAs, and compared across rapid congenic rat breast tissues of untreated normal control, MNU-treated adjacent normal, and tumor tissue. Only the miR-574-3p was validated by a follow up qPCR displaying the same fold trend, with about a 11-fold reduction in tumor tissue compared to normal tissue $(p=0.0022)$ (Figure 9 A). The miRNAs mmu-miR-344 and mmumiR-543 were found to have an opposite fold change by validation qPCR than previously found with the array. The mmu-miR-344 showed a significant decrease of about 4- fold in expression in tumor tissue compared to normal tissue $(p=0.0098)$. The mmu-miR-543 showed about a 1.5 - fold decrease in tumor samples, however this decrease was not significantly different between normal and tumor tissue $(p=0.1620)$. Individual data points show one of the four tumor expression levels was in the range of normal tissue, while the other three tumor mmu-miRNA-543 expression levels showed an extreme decrease in expression compared to normal tissue. If the one tumor sample, expressing in the normal expression level range, is removed, then the tumor tissue has about a 13- fold reduction in expression compared to normal tissue, and is found to be significantly different between normal and tumor tissue $(p=0.0011)$ (Figure 9 B). 


\section{FIGURE 7}

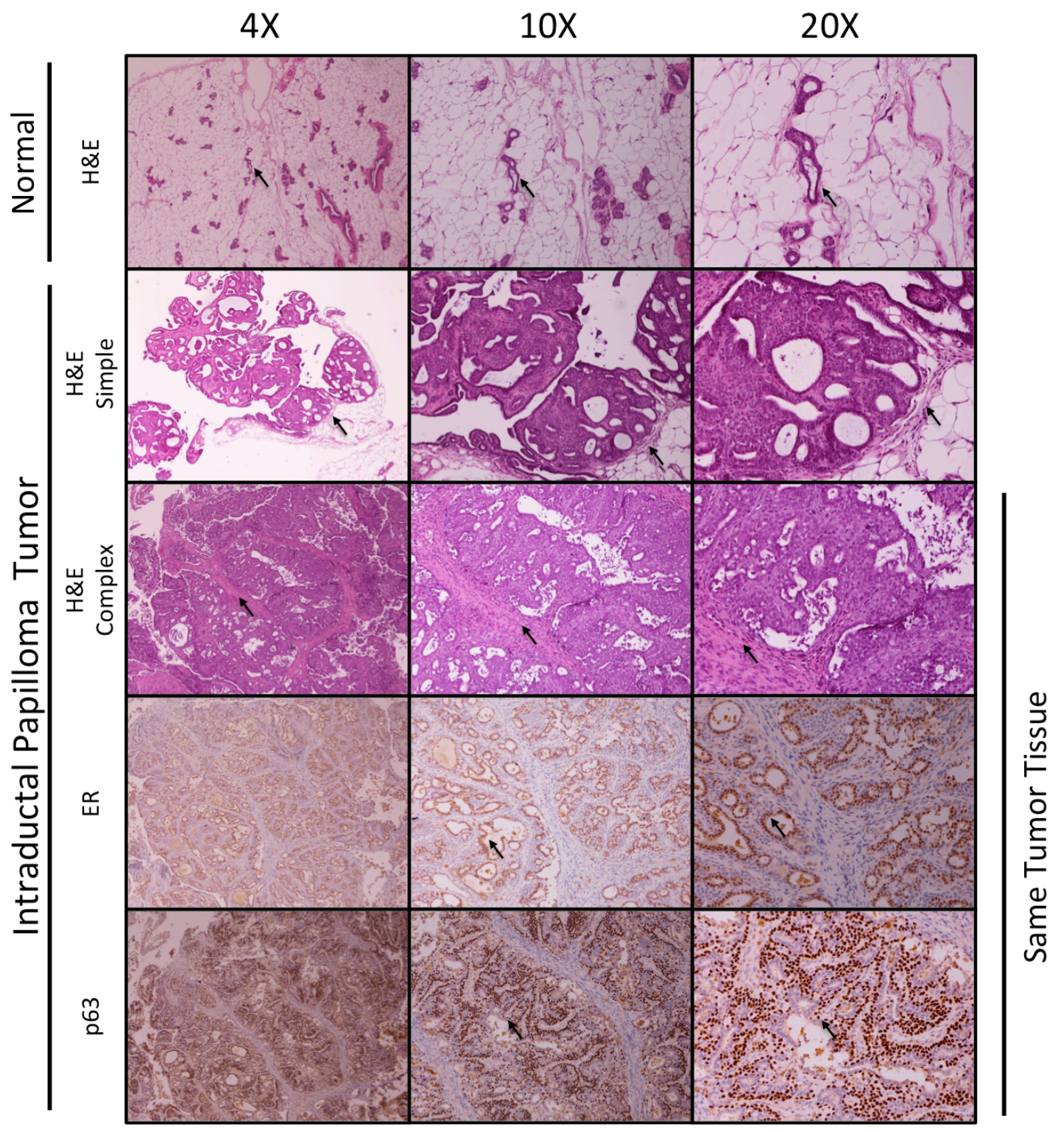

Figure 7. Photomicrographs of H\&E and immunohistochemistry slides. The three columns show different magnifications of sectioned tissue. The first row shows the normal untreated mammary gland tissue by H\&E staining (black arrow indicates the presence of a normal mammary gland duct). The remaining four rows are of tumor tissue. The second row is a H\&E slide showing the intraductal papilloma proliferating into the lumen with a well defined boundary (black arrow marks the separation of tumor and normal tissue). The third row is a H\&E stain of a intraductal papilloma containing hyperplasic cells and fibrovascular cores (black arrow indicates a fibrovascular core). The fourth row is looking at estrogen receptor (ER) expression (black arrow indicates ER positive epithelial cells). The fifth row indicates p63 expression, which is a marker of myoepithelial cells (black arrows indicate positive p63 cells being located below the epithelial cells). 


\section{FIGURE 8}

A

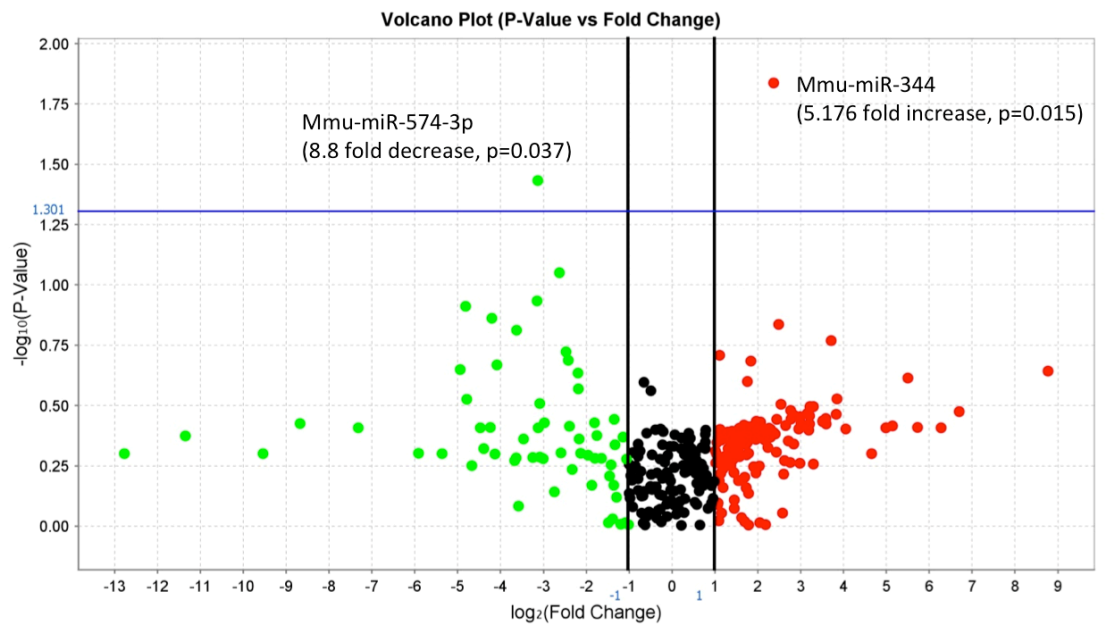

B

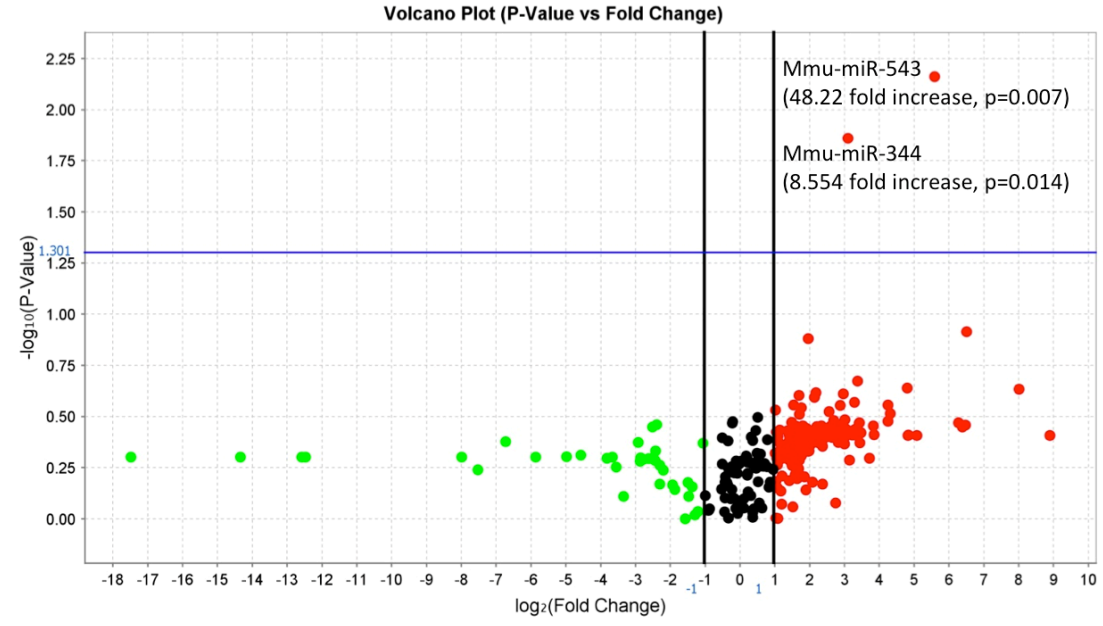

Figure 8. Volcano plots of miRNA levels between different tissues.

Volcano plot of tumor tissue miRNA compared with either adjacent normal or untreated normal tissue. Fold change boundary is set to 2- fold and the $p$ boundary is set to 0.005 . A. Two miRNAs are shown as significantly different between adjacent normal tissue and tumor tissue miR-574-3p (0.114- fold, $p=0.037$ ) and miR-344 (5.176- fold, $p=0.015)$. Validation by qRT-PCR of miR-344 did not confirm the fold change found in the volcano plot. B. Two miRNAs are shown as significantly different between untreated normal tissue and tumor tissue miR-543 (48.22- fold, $p=0.037$ ) and miR-344 (5.176- fold, $p=0.015$ ). Validation by qRT-PCRs of both miRNAs did not confirm the fold change found in the volcano plot. 


\section{FIGURE 9}

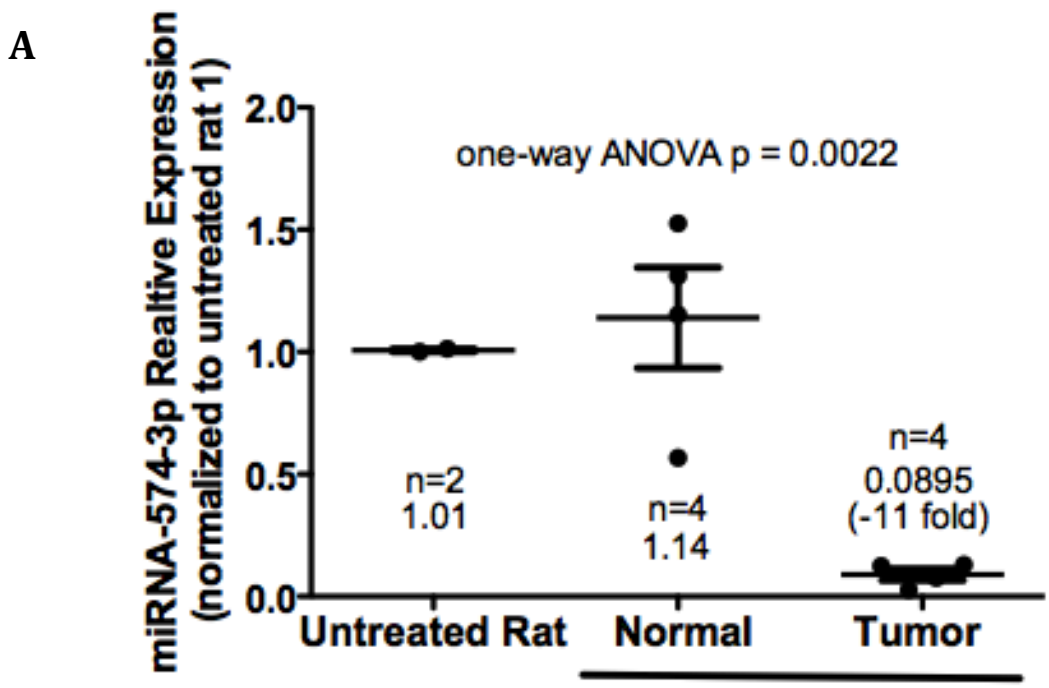

Treated Rat

Rapid Congenic Rat Breast Tissues

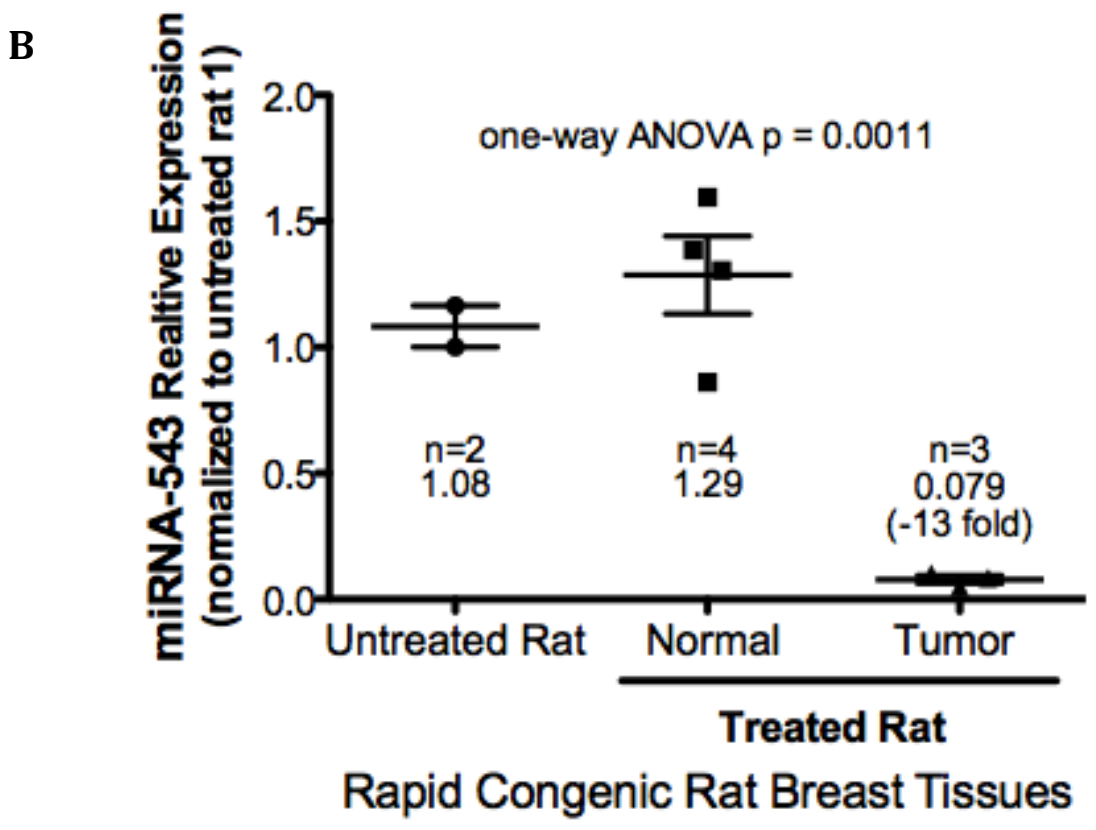

Figure 9. Scatter plots of validation qRT-PCR results for selected miRNAs Scatter plots of qRT-PCR validations for miR-574 and miR-543. A. miR-574-3p validation scatter plots represent the average and the SEM. The miRNA expression shows a fold reduction of about -11 fold, with $p=0.0022$ by one-way ANOVA. B. miR-543 validation scatter plots represent the average and the SEM. The miRNA expression shows a fold reduction of about -13 fold, and with $p=$ 0.0022 by a one-way ANOVA. One data point was removed from treated tumor, because it was an outlier. 


\section{DISCUSSION}

The experiments in this thesis were performed to investigate whether there is a difference in MNU-induced tumor formation between rapid and slow congenic Nat2 rats. My hypothesis was that rapid Nat2 congenic rats would develop more tumors than the slow Nat2 congenic rat population. This hypothesis is based on the previously mentioned work in human studies and manipulation of NAT1 in human cancer cell lines. The rapid Nat2 MNU-treated rats developed tumors earlier and developed more tumors over time than the slow Nat2 MNU-treated congenic rats. The incidence of a rat having a tumor was higher in the rapid congenic rat population than in slow congenic rats, $78 \%$ and $30 \%$ respectively. Rapid congenic rats also develop more tumors per rat than the slow congenic rats. The significance level of the incidence and multiplicity was marginal significant, due to sample size.

A common pathology of intraductal papillomas was found for nearly all tumors, except in one rapid Nat2 congenic rat. Intraductal papillomas can have areas of atypical or ductal carcinoma in situ [59]. Intraductal papillomas are often identified in humans by mammogram, MRI, ultrasound, and ductogram. Intraductal papillomas treatment is still debated in literature as to which treatment is best. The seemly common treatment is core-needle biopsy surgical excision. Variables such as size and level of atypical cells determine the need for surgical removal and the chance of upgrading to a malignancy. The fact that only in the 
rapid Nat2 rats a pathology more aggressive than intraductal papillomas was discovered, suggests that rapid Nat2 congenic rats are more susceptible to carcinogenesis.

These findings suggest that higher rat Nat2 activity contributes to an increased susceptibility to tumorigenesis. This thesis is to date the only experiment to look at direct acting carcinogen-induced tumors in congenic animals that have rapid (high level) and slow (low level) of Nat2 activity. This study suggests that the rat Nat2 plays a role in the temporal onset of tumors and in the multiplicity and incidence of tumor development. The role of rat Nat2 in tumorigenesis is not well understood.

Current theories involve folic acid level and acetyl-coenzyme A (AcCoA) level. The only known endogenous human NAT1 substrate is paminobenzoylglutamate (pABG), a catabolite of folate [65]. The reduced forms of folic acid, like the unsubstituted dihydrofolate (DHF) and tetrahydrofolate (THF) are chemically unstable. They spontaneously break apart at the C-9 $\mathrm{N}-10$ bond to yield pteridine and $p$-aminobenzoylglutamate (PABG). These catabolites have not been found to have any known biologic activity. However, human NAT1 has been associated with various birth defects that may be related to deficiencies in folate metabolism $[66,67]$. In the present study, the reasoning is that rapid Nat2 congenic rats are better able to acetylate PABG causing a reduction in the required folic acid compounds. This lowering of folic compounds may hinder DNA repair, protein synthesis and DNA methylation. However, recent research has shown that in wildtype mouse Nat2 mice compared to mice null for Nat2 have no 
difference in the level of pABG in mouse tissues [68]. The same research showed that the folic compound levels were not different between wildtype female mice compared to female mouse Nat2 null mice. This research shows that the folate theory is unlikely.

The AcCoA levels could be lower in rapid Nat2 congenic rats because of increased AcCoA hydrolysis activity of rat Nat2. Human NAT1 and rat Nat2 share identical C-terminal tails responsible for AcCoA hydrolytic activity, and it has been hypothesized that human NAT1 can catalyze the hydrolysis of AcCoA in the absence of any chemical substrate. This hypothesis has gained interest after research showed that mouse Nat2, human NAT1, and various prokaryotic orthologs of human NAT1 are able to hydrolysis AcCoA into CoA and acetate products in the presence of folate and no substrate [69]. The theoretical lowering of AcCoA in the cell could affect several pathways including energy production, fatty acid synthesis, and DNA repair. This theory seems more likely to be the cause of tumorigenic differences between rapid and slow Nat2 congenic rats.

Molecular analysis of the tumors for miRNA differences indicated that miRNA-574-3p was expressed at significantly lower levels in tumor tissue compared to normal control/adjacent tissue. The miRNA miR-574-3p has been the center of several articles, particularly on bladder cancer [60]. The authors showed that miR-574-3p levels were decreased in bladder cancer cell lines, and once levels were restored cell lines decreased in proliferation, wound healing, and invasion ability. They also showed that apoptosis was elevated in miR-574$3 p$ restored cell lines. Another study found miR-574-3p expression to be reduced 
mainly in early stages of gastric cancer or in cancer with high level of differentiation [61]. Similar to the previous paper, the authors confirmed that miR574-3p inhibited the proliferation, migration and invasion of gastric cancer cells transfected to express the miRNA. Researchers also found that miR-574-3p is reduced in prostate cancer cell lines, and that the drug genistein is able to cause an increase in miR-574-3p expression [62]. The miR-574-3p is also downregulated in esophageal cancer tissue [63].

Publications on miRNA-574-3p are only from recent years, however there seems to be no paper connecting this miRNA to breast cancer. So this thesis may serve as an indication that miRNA-574-3p is not only associated with bladder, colon, esophageal, and prostate cancer, but may also be associated with breast cancer. This finding was observed in tumors classified as intraductal papillomas, since that was the overwhelming majority of tumors. So further experiments could be done to see if this miRNA is down regulated in other breast cancer pathologies.

A major issue with miRNA-574-3p is that the miRNA is not currently identified in the rat genome. However our experiments have shown that there is a dramatic difference in miRNA expression between tumor tissue and normal tissue using commercial primers for miRNA-574-3p expression. Also the synteny region is shared between human and rat genome at the region where miRNA$574-3 p$ is found in humans. Given how new the study of miRNA-574-3p is, it is reasonable to assume the sequence exists in the rat genome, however not identified yet. 
An additional miRNA of interest, found while comparing rapid intraductal papilloma tissue and rapid control normal tissue, was the mmu-miR-543-3p. A recent publication has shown that miRNA-543 expression is decreased in endometrial cancer [64]. In the same article, they show that miRNA-543 acts as a tumor suppressor by decreasing Focal adhesion kinase (FAK) and Twist homolog 1 (TWIST1) expression. The genomic sequence for miRNA-543 has already been identified in the rat genome. Since the miRNA-543 has been located in the rat genome, this miRNA could be explored further to find evidence of miRNA-543 involvement in breast cancer.

We have shown in this study that MNU-induced tumors differed between rapid and slow congenic Nat2 rats consistent with the initial hypothesis that rapid congenic Nat2 rats would develop more tumors than the slow congenic Nat2 rat population. This finding is also consistent with previous work in human studies and manipulation of human NAT1 in cancer cell lines. With the use of MNU, we showed a statistical temporal difference between rapid and slow congenic Nat2 rats with the development of $\mathrm{MNU}$-induced tumors. Marginal significance in multiplicity and incidence of tumors induced in rapid and slow congenic rat populations was observed. The results suggest a role of human NAT1 in tumorigenesis, and for the first time an association of miRNA-574-3p and breast cancer. 


\section{SUMMARY AND CONCLUSIONS}

\section{STRENGTHS OF THIS WORK}

This work suggests that human NAT1, with the use of the ortholog rat Nat2 in congenic rats, plays an important role in tumorigenic incidence and onset. The strengths of this study are the congenic rat model and the similarity of human NAT1 and rat Nat2. Our laboratory made the congenic Fischer 344 rat stains several years ago, and characterized the differences between rapid and slow Nat2 congenic rats in previous publications. The rapid and slow Nat2 congenic F344 rat stains were derived by the same approach, so the genetic background between rapid and slow congenic rats will be more than $99.9 \%$ similar. This very close similarity allows us to compare rapid and slow Nat2 with minimal influence of strain differences besides the Nat2 gene. As mentioned in

the introduction, human NAT1 and rat Nat2 share over $83 \%$ amino acid sequence homology, with no differences in the active site or the C-terminal tail. The rat breast cancer model is a strength because we can measure palpable tumors in live animals over time. In theory this study could be conducted on almost any form of inducible cancer.

\section{CAVEATS AND WEAKNESSES}

Chemically induced tumors are affected by variable, yet controllable, factors like the inducing carcinogen, age of administration, reproductive history, 
and diet. Diet and reproductive history of these rats are the same for both rapid and slow congenic rats. Chemically induced breast tumors have been induced for several decades with the administration of MNU. MNU is a direct acting DNA alkylating agent that does not need biotransformation before forming DNA adducts. It has been previously shown that sexually immature F344 rats (at 3 weeks of age) are more susceptible to mammary carcinogenic effects from MNU than mature rats (8 weeks of age) [45]. Developmental studies on the rats over time can be done to see if $\mathrm{O}^{6}$-alkyguanine-DNA alkyltransferase, also known as $0^{6}$-methylguanine DNA methyltransferase, the only enzyme shown to have a chemopreventive role in MNU toxicity varies between rapid and slow Nat2 congenic rats [51]. 


\section{FUTURE DIRECTIONS}

Arylamine $\mathrm{N}$-acetyltransferase 1 (NAT1), a well-known phase II metabolic enzyme, has been associated with breast cancer. Breast cancer is estimated to have more new cases than any other type of cancer in United States women and has the second highest mortality rate [1]. The ultimate goal of this project is to advance the understanding of NAT1 in breast cancer, which can in turn lead to improvements in breast cancer prevention and/or treatment. Overexpression of NAT1 in a normal human mammary luminal epithelial cell line (HB4a) enhanced cell proliferation [2]. The use of siRNA against NAT1 as well as small molecule inhibitors has shown that NAT1 is involved in cell-to-cell contact inhibition in several cancer cell lines [3, 4]. Microarray data have shown a strong positive correlation between the overexpression of NAT1 mRNA and breast cancers that are estrogen receptor positive [5]. To investigated this further, I propose in my $\mathrm{PhD}$ dissertation project to investigate the differences in initiation and progression of cancer in vivo between high (rapid) and low (slow) NAT activity rats, and use these two congenic rat strains, along with NAT1 expression modified cancer cell lines, to investigate endogenous mechanism(s) of NAT1 involvement with breast cancer. The in vivo studies will use a novel congenic rat model that was produced by our lab previously, that have been used to observe differences in drug metabolism between rapid and slow acetylator phenotypes. The rats are Fischer 344 background with one strain 
having a rapid rat Nat2 gene and the other strain is a slow rat Nat2. Rat Nat2 is an ortholog for human NAT1 because it has shown similar substrate specificity to human NAT1. The published work on NAT1 in breast cancer leads us to hypothesize that high Nat2 activity in rats would correspond to an increase number of chemically induced tumors by a direct acting carcinogen methylnitrosourea $(\mathrm{MNU})$. In testing that hypothesis we have shown that indeed chemically induced breast tumors in prepubescent female rats are elevated in rapid congenic rat compared to the slow congenic strains. The results suggest an important role for NAT1 in tumorigenesis, but further studies are needed to confirm the results and to help us understand the mechanism by which rat Nat2 is affecting tumorigenesis. 


\section{REFERENCES}

1. Hein, D.W., et al., Molecular genetics and epidemiology of the NAT1 and NAT2 acetylation polymorphisms. Cancer Epidemiol Biomarkers Prev, 2000. 9(1): p. 29-42.

2. Boukouvala, S. and E. Sim, Structural analysis of the genes for human arylamine $\mathrm{N}$-acetyltransferases and characterisation of alternative transcripts. Basic Clin Pharmacol Toxicol, 2005. 96(5): p. 343-51.

3. Pacifici, G.M., C. Bencini, and A. Rane, Acetyltransferase in humans: development and tissue distribution. Pharmacology, 1986. 32(5): p. 28391.

4. Adam, P.J., et al., Arylamine N-Acetyltransferase-1 Is Highly Expressed in Breast Cancers and Conveys Enhanced Growth and Resistance to Etoposide in Vitro. Molecular Cancer Research, 2003. 1(11): p. 826-835.

5. Tooker, P., et al., Bexarotene (LGD1069, Targretin), a selective retinoid $X$ receptor agonist, prevents and reverses gemcitabine resistance in NSCLC cells by modulating gene amplification. Cancer Res, 2007. 67(9): p. 442533.

6. Wakefield, L., et al., Arylamine N-acetyltransferase I expression in breast cancer cell lines: A potential marker in estrogen receptor-positive tumors. Genes Chromosomes \& Cancer, 2008. 47(2): p. 118-126.

7. Tiang, J.M., N.J. Butcher, and R.F. Minchin, Small molecule inhibition of arylamine $\mathrm{N}$-acetyltransferase Type $I$ inhibits proliferation and invasiveness of MDA-MB-231 breast cancer cells. Biochemical and Biophysical Research Communications, 2010. 393(1): p. 95-100.

8. Tiang, J.M., et al., RNAi-Mediated Knock-Down of Arylamine Nacetyltransferase-1 Expression Induces E-cadherin Up-Regulation and Cell-Cell Contact Growth Inhibition. Plos One, 2011. 6(2).

9. Butcher, N.J. and R.F. Minchin, Arylamine N-acetyltransferase 1: a novel drug target in cancer development. Pharmacol Rev, 2012. 64(1): p. 14765.

10. Perou, C.M., et al., Molecular portraits of human breast tumours. Nature, 2000. 406(6797): p. 747-52.

11. Sorlie, T., et al., Gene expression patterns of breast carcinomas distinguish tumor subclasses with clinical implications. Proc Natl Acad Sci U S A, 2001. 98(19): p. 10869-74.

12. van 't Veer, L.J., et al., Gene expression profiling predicts clinical outcome of breast cancer. Nature, 2002. 415(6871): p. 530-6.

13. Weigelt, B., et al., Gene expression profiles of primary breast tumors maintained in distant metastases. Proc Natl Acad Sci U S A, 2003. 100(26): p. 15901-5. 
14. Bertucci, F., et al., Identification and validation of an ERBB2 gene expression signature in breast cancers. Oncogene, 2004. 23(14): p. 256475.

15. Abba, M.C., et al., Gene expression signature of estrogen receptor alpha status in breast cancer. BMC Genomics, 2005. 6: p. 37.

16. Knuutila, S., et al., DNA copy number losses in human neoplasms. Am J Pathol, 1999. 155(3): p. 683-94.

17. Farmer, P., et al., Identification of molecular apocrine breast tumours by microarray analysis. Oncogene, 2005. 24(29): p. 4660-71.

18. Alimonti, A., et al., Subtle variations in Pten dose determine cancer susceptibility. Nat Genet, 2010. 42(5): p. 454-8.

19. Smid, M., et al., Genes associated with breast cancer metastatic to bone. J Clin Oncol, 2006. 24(15): p. 2261-7.

20. Casey, T., et al., Molecular signatures suggest a major role for stromal cells in development of invasive breast cancer. Breast Cancer Res Treat, 2009. 114(1): p. 47-62.

21. Badawi, A.F., et al., Role of aromatic amine acetyltransferases, NAT1 and NAT2, in carcinogen-DNA adduct formation in the human urinary bladder. Cancer Res, 1995. 55(22): p. 5230-7.

22. Bell, D.A., et al., Polymorphism in the N-acetyltransferase 1 (NAT1) polyadenylation signal: association of NAT1*10 allele with higher $\mathrm{N}$ acetylation activity in bladder and colon tissue. Cancer Res, 1995. 55(22): p. 5226-9.

23. Wang, D., et al., Human $\mathrm{N}$-acetyltransferase $1{ }^{*} 10$ and ${ }^{*} 11$ alleles increase protein expression through distinct mechanisms and associate with sulfamethoxazole-induced hypersensitivity. Pharmacogenet Genomics, 2011. 21(10): p. 652-64.

24. Millikan, R.C., et al., Cigarette smoking, $\mathrm{N}$-acetyltransferases 1 and 2, and breast cancer risk. Cancer Epidemiology Biomarkers \& Prevention, 1998. 7(5): p. 371-378.

25. Lilla, C., et al., Effect of NAT1 and NAT2 genetic polymorphisms on colorectal cancer risk associated with exposure to tobacco smoke and meat consumption. Cancer Epidemiology Biomarkers \& Prevention, 2006. 15(1): p. 99-107.

26. Bell, D.A., et al., Polyadenylation polymorphism in the acetyltransferase 1 gene (NAT1) increases risk of colorectal cancer. Cancer Res, 1995. 55(16): p. 3537-42.

27. Gemignani, F., et al., Development of lung cancer before the age of 50: the role of xenobiotic metabolizing genes. Carcinogenesis, 2007. 28(6): p. 1287-1293.

28. Li, D., et al., Polymorphisms of cytochrome P4501A2 and Nacetyltransferase genes, smoking, and risk of pancreatic cancer. Carcinogenesis, 2006. 27(1): p. 103-11.

29. Taylor, J.A., et al., The role of $\mathrm{N}$-acetylation polymorphisms in smokingassociated bladder cancer: evidence of a gene-gene-exposure three-way interaction. Cancer Res, 1998. 58(16): p. 3603-10. 
30. $\mathrm{Gu}$, J., et al., Effects of $\mathrm{N}$-acetyl transferase 1 and 2 polymorphisms on bladder cancer risk in Caucasians. Mutat Res, 2005. 581(1-2): p. 97-104.

31. Gong, C., et al., A meta-analysis of the NAT1 and NAT2 polymorphisms and prostate cancer: a huge review. Med Oncol, 2011. 28(1): p. 365-76.

32. Dhaini, H.R. and G.N. Levy, Arylamine N-acetyltransferase 1 (NAT1) genotypes in a Lebanese population. Pharmacogenetics, 2000. 10(1): p. 79-83.

33. Walraven, J.M., J.O. Trent, and D.W. Hein, Structure-function analyses of single nucleotide polymorphisms in human $\mathrm{N}$-acetyltransferase 1. Drug Metab Rev, 2008. 40(1): p. 169-84.

34. Bouchardy, C., et al., N-acetyltransferase NAT1 and NAT2 genotypes and lung cancer risk. Pharmacogenetics, 1998. 8(4): p. 291-8.

35. Millner, L.M., et al., Phenotype of the most common "slow acetylator" arylamine $\mathrm{N}$-acetyltransferase 1 genetic variant (NAT1*14B) is substratedependent. Drug Metab Dispos, 2012. 40(1): p. 198-204.

36. Wick, M.J. and P.E. Hanna, Bioactivation of N-arylhydroxamic acids by rat hepatic $\mathrm{N}$-acetyltransferase. Detection of multiple enzyme forms by mechanism-based inactivation. Biochemical pharmacology, 1990. 39(6): p. 991-1003.

37. Hein, D.W., et al., Extrahepatic expression of the $\mathrm{N}$-acetylation polymorphism toward arylamine carcinogens in tumor target organs of an inbred rat model. The Journal of pharmacology and experimental therapeutics, 1991. 258(1): p. 232-6.

38. Hein, D.W., et al., Rodent models of the human acetylation polymorphism: comparisons of recombinant acetyltransferases. Mutation research, 1997. 376(1-2): p. 101-6.

39. Walraven, J.M., M.A. Doll, and D.W. Hein, Identification and characterization of functional rat arylamine $\mathrm{N}$-acetyltransferase 3 : comparisons with rat arylamine $\mathrm{N}$-acetyltransferases 1 and 2. The Journal of pharmacology and experimental therapeutics, 2006. 319(1): p. 369-75.

40. Goodfellow, G.H., J.M. Dupret, and D.M. Grant, Identification of amino acids imparting acceptor substrate selectivity to human arylamine acetyltransferases NAT1 and NAT2. The Biochemical journal, 2000. 348 Pt 1: p. 159-66.

41. Mushtaq, A., M. Payton, and E. Sim, The $\mathrm{COOH}$ terminus of arylamine Nacetyltransferase from Salmonella typhimurium controls enzymic activity. The Journal of biological chemistry, 2002. 277(14): p. 12175-81.

42. Shepel, L.A. and M.N. Gould, The genetic components of susceptibility to breast cancer in the rat. Prog Exp Tumor Res, 1999. 35: p. 158-69.

43. Hein, D.W., et al., Acetylator phenotype-dependent and -independent expression of arylamine $\mathrm{N}$-acetyltransferase isozymes in rapid and slow acetylator inbred rat liver. Drug metabolism and disposition: the biological fate of chemicals, 1991. 19(5): p. 933-7.

44. Doll, M.A. and D.W. Hein, Cloning, sequencing and expression of NAT1 and NAT2 encoding genes from rapid and slow acetylator inbred rats. Pharmacogenetics, 1995. 5(4): p. 247-51. 
45. Ariazi, J.L., et al., Mammary glands of sexually immature rats are more susceptible than those of mature rats to the carcinogenic, lethal, and mutagenic effects of N-nitroso-N-methylurea. Mol Carcinog, 2005. 43(3): p. $155-64$.

46. Pegg, A.E., Methylation of the 06 position of guanine in DNA is the most likely initiating event in carcinogenesis by methylating agents. Cancer Invest, 1984. 2(3): p. 223-31.

47. Shrivastav, N., D. Li, and J.M. Essigmann, Chemical biology of mutagenesis and DNA repair: cellular responses to DNA alkylation. Carcinogenesis, 2010. 31(1): p. 59-70.

48. Fortini, P., et al., The base excision repair: mechanisms and its relevance for cancer susceptibility. Biochimie, 2003. 85(11): p. 1053-71.

49. Engelward, B.P., et al., A chemical and genetic approach together define the biological consequences of 3-methyladenine lesions in the mammalian genome. J Biol Chem, 1998. 273(9): p. 5412-8.

50. Loechler, E.L., C.L. Green, and J.M. Essigmann, In vivo mutagenesis by O6-methylguanine built into a unique site in a viral genome. Proc Natl Acad Sci U S A, 1984. 81(20): p. 6271-5.

51. Margison, G.P. and M.F. Santibanez-Koref, O6-alkylguanine-DNA alkyltransferase: role in carcinogenesis and chemotherapy. Bioessays, 2002. 24(3): p. 255-66.

52. York, S.J. and P. Modrich, Mismatch repair-dependent iterative excision at irreparable O6-methylguanine lesions in human nuclear extracts. J Biol Chem, 2006. 281(32): p. 22674-83.

53. Karran, P. and M.G. Marinus, Mismatch correction at O6-methylguanine residues in E. coli DNA. Nature, 1982. 296(5860): p. 868-9.

54. Delaney, J.C. and J.M. Essigmann, Effect of sequence context on O(6)methylguanine repair and replication in vivo. Biochemistry, 2001. 40(49): p. $14968-75$.

55. Franco, R., et al., Oxidative stress, DNA methylation and carcinogenesis. Cancer Lett, 2008. 266(1): p. 6-11.

56. Xiao, W. and L. Samson, In vivo evidence for endogenous DNA alkylation damage as a source of spontaneous mutation in eukaryotic cells. Proc Natl Acad Sci U S A, 1993. 90(6): p. 2117-21.

57. Fu, D., J.A. Calvo, and L.D. Samson, Balancing repair and tolerance of DNA damage caused by alkylating agents. Nat Rev Cancer, 2012. 12(2): p. 104-20.

58. Hein, D.W., et al., Systemic functional expression of $\mathrm{N}$-acetyltransferase polymorphism in the F344 Nat2 congenic rat. Drug Metab Dispos, 2008. 36(12): p. 2452-9.

59. Sabel, M.S. Overview of benign breast disease. UpToDate 2013 Mar 6, 2013.; Available from: http://www.uptodate.com/contents/overview-ofbenign-breast-disease - $\mathrm{H} 35$.

60. Tatarano, S., et al., Novel oncogenic function of mesoderm development candidate 1 and its regulation by MiR-574-3p in bladder cancer cell lines. Int J Oncol, 2012. 40(4): p. 951-9. 
61. Su, Y., et al., Aberrant expression of microRNAs in gastric cancer and biological significance of miR-574-3p. Int Immunopharmacol, 2012. 13(4): p. 468-75.

62. Chiyomaru, T., et al., Genistein up-regulates tumor suppressor microRNA574-3p in prostate cancer. PLoS One, 2013. 8(3): p. e58929.

63. Liu, S.G., et al., Differential expression of miRNAs in esophageal cancer tissue. Oncol Lett, 2013. 5(5): p. 1639-1642.

64. Bing, L., et al., MicroRNA-543 suppresses endometrial cancer oncogenicity via targeting FAK and TWIST1 expression. Arch Gynecol Obstet, 2014.

65. Wakefield, L., et al., Deletion of a xenobiotic metabolizing gene in mice affects folate metabolism. Biochemical and Biophysical Research Communications, 2007. 364(3): p. 556-60.

66. Jensen, L.E., et al., The NAT1 C1095A polymorphism, maternal multivitamin use and smoking, and the risk of spina bifida. Birth defects research. Part A, Clinical and molecular teratology, 2005. 73(7): p. 512-6.

67. Lammer, E.J., et al., Maternal smoking and the risk of orofacial clefts: Susceptibility with NAT1 and NAT2 polymorphisms. Epidemiology, 2004. 15(2): p. 150-6.

68. Witham, K.L., et al., 5-methyl-tetrahydrofolate and the Sadenosylmethionine cycle in C57BL/6J mouse tissues: gender differences and effects of arylamine N-acetyltransferase-1 deletion. PLoS One, 2013. 8(10): p. e77923.

69. Laurieri, N., et al., From Arylamine N-Acetyltransferase to FolateDependent Acetyl CoA Hydrolase: Impact of Folic Acid on the Activity of (HUMAN)NAT1 and Its Homologue (MOUSE)NAT2. PLoS One, 2014. 9(5): p. e96370. 


\section{ABBREVIATIONS}

\begin{tabular}{ll} 
ANOVA & Adenine \\
Arg & Analysis of variance \\
CDNA & Arginine \\
$\mathrm{CO}_{2}$ & Complementary deoxyribonucleic acid \\
$\mathrm{DHF}$ & Dihydrofolate \\
$\mathrm{ER}$ & Estrogen receptor \\
$\mathrm{F} 344$ & Fischer 344 rat \\
$\mathrm{G}$ & Guanine \\
$\mathrm{H}_{2} \mathrm{O}_{2}$ & Hydrogen peroxide \\
$\mathrm{H} \& \mathrm{E}$ & Hematoxylin and eosin \\
$\mathrm{IP}$ & Intraductal papillomas \\
$\mathrm{kg}$ & kilogram \\
$\mathrm{miRNA} / \mathrm{miR}$ & Micro ribonucleic acid \\
$\mathrm{MRI}$ & Magnetic resonance imaging \\
$\mathrm{mg}$ & milligram \\
$\mathrm{ml}$ & milliiter \\
$\mathrm{MNU}$ & methyl-nitrosourea/N-methylnitrosourea/1-nitroso-1-methylurea \\
$\mathrm{N}$ & Nitrogen \\
$\mathrm{NAT1}$ & Human $\mathrm{N}-$ Acetyltransferase 1 \\
\hline
\end{tabular}




$\begin{array}{ll}\text { NAT2 } & \text { Human N-Acetyltransferase 2 } \\ \text { Nat1 } & \text { Rodent N-Acetyltransferase 1 } \\ \text { Nat2 } & \text { Rodent N-Acetyltransferase 2 } \\ \text { O } & \text { Oxygen } \\ \text { PABG } & \text { p-aminobenzoylglutamate } \\ \text { PCR } & \text { Polymerase chain reaction } \\ \text { qPCR } & \text { Real-time quantitative polymerase chain reation } \\ \text { Phe } & \text { Phenylalanine } \\ \text { RNA } & \text { Ribonucleic acid } \\ \text { SEM } & \text { Standard error mean } \\ \text { siRNA } & \text { Small interfering ribonucleic acid } \\ \text { T } & \text { Thymine } \\ \text { THF } & \text { Tetrahydrofolate } \\ \text { Tyr } & \text { Tyrosine } \\ \text { Val } & \text { Valine } \\ \text { WKY } & \text { Wistar Kyoto rat } \\ { }^{\circ} \mathrm{C} & \text { Degrees Celsius } \\ \mu & \text { Micro }\end{array}$




\title{
CURRICULUM VITAE
}

\author{
Marcus W. Stepp \\ University of Louisville School of Medicine \\ Department of Pharmacology and Toxicology \\ Louisville, KY 40202 \\ mwstep03@louisville.edu \\ 502-852-6284
}

\section{EDUCATION}

2006-2010 Rose-Hulman Institute of Technology

B.S., Applied Biology and Biochemistry \& Molecular Biology

\section{PROFESSIONAL EXPERIENCE}

2010-2011 Research Technician, University of Louisville, Division of Pulmonary, Critical Care, and Sleep Disorders Medicine

2009-2010 Undergraduate Senior Research, Rose-Hulman Institute of Technology

2009 Praktikum researcher, Universitatsklinikum Essen, Institut für Transfusionsmedizin

2007, 2008 Intern Researcher, Cincinnati Children's Hospital, Division of Experimental Hematology

\section{LEADERSHIP}

2014-2015 President, Pharmacology and Toxicology Graduate Student Organization

2013-2014 Vice President, Pharmacology and Toxicology Graduate Student Organization

2013-2015 Student Representative, Student Affairs Committee

2013-2015 Class Representative, University of Louisville

2008-2010 Treasurer, Student Activities Board, Rose Hulman Institute of Technology

2008-2009 Vice President, International Society for Pharmaceutical Engineering, Rose Hulman Institute of Technology

2007-2008 Encore Committee Chairman, Student Activities Board, Rose Hulman Institute of Technology 


\section{PROFESSIONAL SOCIETIES}

2013-2014 American Society for Pharmacology and Experimental Therapeutics (ASPET)

2013-2014 Society of Toxicology (SOT)

2013-2014 Ohio Valley Chapter of the Society of Toxicology (OVSOT)

2008-2014 Alpha Chi Sigma (Colligate and Professional)

2007-2009 International Society for Pharmaceutical Engineering (ISPE)

\section{PUBLICATIONS}

\section{Papers}

1. Stepp, M. W., R. J. Folz, J. Yu, I. N. Zelko (2014). The c10orf10 gene product is a new link between oxidative stress and autophagy. Biochimica et Biophysica Acta (BBA) - Molecular Cell Research, 1843(6): p. 10761088,

2. Zelko, I. N., M. W. Stepp and R. J. Folz (2013). "A bioluminescent transgenic mouse model: real-time in vivo imaging of antioxidant EC-SOD gene expression and regulation by interferon gamma." Gene 530(1): 7582.

3. Millner, L. M., M. A. Doll, M. W. Stepp, J. C. States and D. W. Hein (2012). "Functional analysis of arylamine $\mathrm{N}$-acetyltransferase 1 (NAT1) NAT1*10 haplotypes in a complete NATb mRNA construct." Carcinogenesis 33(2): 348-355.

4. Zelko, I. N., M. W. Stepp, A. L. Vorst and R. J. Folz (2011). "Histone acetylation regulates the cell-specific and interferon-gamma-inducible expression of extracellular superoxide dismutase in human pulmonary arteries." Am J Respir Cell Mol Biol 45(5): 953-961.

\section{Abstracts - National//nternational}

1. Marcus W. Stepp, Mark A. Doll, Mary Ann G. Sanders, and David W. Hein. 2013. Rapid Arylamine N-Acetyltransferase Congenic Rats Show Increase of Chemically Induced Breast Tumors by $N$-methylnitrosourea. Oral presentation, Sixth International Workshop on Arylamine Nacetyltransferases, Toronto, ON

\section{Abstracts - Regional}

1. Marcus Stepp, Mark Doll, J. Christopher States, David Hein. 2014. Incidence of N-methylnitrosourea-induced breast tumors differ between rapid and slow acetylator congenic rat strains. Poster presentation. Great Lakes Drug Metabolism and Disposition Group 2014 Meeting, Indianapolis, IN

2. Marcus Stepp, Mark Doll, Mary Ann Sanders, David Hein. 2013. Fischer 344 rat strains congenic at arylamine $\mathrm{N}$-acetyltransferase differ in breast tumorigenesis induced by1-methyl-1-nitrosourea. Poster presentation. James Graham Brown Cancer Center Annual Retreat 2013, Louisville, KY 
3. Marcus Stepp, Mark Doll, Mary Ann Sanders, David Hein. 2013. Fischer 344 rat strains congenic at arylamine $\mathrm{N}$-acetyltransferase differ in breast tumorigenesis induced by $\mathrm{N}$-methylnitrosourea. Oral and poster presentation. Ohio Valley Society of Toxicology 2013 Annual Meeting, Louisville, KY

4. Marcus Stepp, Mark Doll, Mary Ann Sanders, David Hein. 2013. Fischer 344 rat strains congenic at arylamine $\mathrm{N}$-acetyltransferase differ in breast tumorigenesis induced by $\mathrm{N}$-methylnitrosourea. Poster presentation. Research! Louisville 2013, Louisville, KY

5. Marcus Stepp, Mark Doll, Lori Millner, J. Christopher States, David Hein. 2012. Functional analysis of arylamine $\mathrm{N}$-acetyltransferase 1 (NAT1) NAT1*10 haplotype in NATa mRNA constructs. Poster presentation, James Graham Brown Cancer Center Annual Retreat 2012, Louisville, KY

6. Marcus Stepp, Mark Doll, Lori Millner, J. Christopher States, David Hein. 2012. Functional analysis of arylamine $\mathrm{N}$-acetyltransferase 1 (NAT1) NAT1*10 haplotype in NATa mRNA constructs. Poster presentation, Research! Louisville 2012, Louisville, KY

7. Igor Zelko, Marcus Stepp, Jerry Yu, Rodney Folz. 2011. Regulation of decidual protein induced by progesterone (DEPP) gene expression by extracellular oxidative stress and its role in autophagy induction. Poster presentation, Research! Louisville 2011, Louisville, KY

\section{PRESENTATIONS}

1. Poster presentation, 5/2014, Great Lakes Drug Metabolism and Disposition Group 2014 Meeting, Indianapolis, IN

2. Poster presentation, 10/2013, James Graham Brown Cancer Center Annual Retreat 2013, Louisville, KY

3. Oral Presentation, 10/2013, Sixth International Workshop on Arylamine $\mathrm{N}$-acetyltransferases, Toronto, ON

4. Oral Presentation, 9/2013, Ohio Valley Society of Toxicology 2013 Annual Meeting, Louisville, KY

5. Poster presentation, 9/2013, Research! Louisville 2013, Louisville, KY

6. Poster presentation, 10/2012James Graham Brown Cancer Center Annual Retreat 2012, Louisville, KY

7. Poster presentation, 9/2012, Research! Louisville 2012, Louisville, KY

8. Departmental Seminar, 3/2012, University of Louisville, Department of Pharmacology and Toxicology, Louisville, KY

9. Oral Presentation, 2010, ABBE Senior Research Day, Rose-Hulman Institute of Technology, Terre Haute, IN

10. Poster presentation, 2008, IRC Undergraduate Student Research Symposium, Rose-Hulman Institute of Technology, Terre Haute, IN

11. Poster Presentation, 2008, Capstone Poster Presentation, University of Cincinnati, Cincinnati, $\mathrm{OH}$ 